\title{
The Effect of Options on Information Acquisition and Asset Pricing*
}

\author{
Shiyang Huang \\ London School of Economics and University of Hong Kong
}

This Version: May, 2015

\begin{abstract}
We study the effect of introducing an options market on investors' incentive to collect private information in a rational expectation equilibrium model. We show that an options market has two effects on information acquisition: a negative effect, as options act as substitutes for information, and a positive effect, as informed investors have less need for options and can earn profits from selling them. When the population of informed investors is high due to low information acquisition cost, the supply for options is large, leading to low option prices. Low option prices in turn induce investors to use options instead of information to reduce risk, while informed investors earn little profits from selling options to cover their information acquisition cost. Introducing an options market thus decreases investors' incentive to acquire information, and the prices of the underlying assets become less informative, leading to lower prices and higher volatilities. A dynamic extension of this analysis shows that introducing an options market increases the price reactions to earnings announcements. However, when the information acquisition cost is high, the opposite effects arise. Further analysis shows that our results are robust for more general derivatives. These results provide a potentially unified theory to reconcile the conflicting empirical findings on the options listing of individual stocks in both the U.S. market and international markets.
\end{abstract}

KEYWORDS: Option, information acquisition cost, rational expectation equilibrium, derivatives

JEL: G12, G13, G14

${ }^{*}$ I would like to thank Bradyn Breon-Drish, Georgy Chabakauri, Daniel Ferreira, Jarrad Harford, Dong Lou, Frank de Jong, Christopher Polk, Tiago Da Silva Pinheiro, Rohit Rahi, Eduardo Schwartz, Dimitri Vayanos, Liyan Yang, Bart Zhou, Cheng Zhang, Haoxiang Zhu, Hongda Zhong, Yao Zeng and all participants in seminars in London School of Economics, 2015 SFS Finance Cavalcade, AFBC PhD Forum and AFBC 2014, and Paris December Finance Meeting 2014, Leeds University and Tilburg University. Thanks for Best Paper Award of Paris December Finance Meeting 2014. All remaining errors are my own. Huang is from the London School of Economics. Email addresses: s.huang5@lse.ac.uk. 


\section{Introduction}

As one of the largest derivative markets, the options market has experienced tremendous growth in the past decade(see Figure 1). ${ }^{1}$ Further, the effect of options listing on the underlying asset market is a hot topic in policy, industry and academia, and it has become extremely important since the financial crisis of 2007-08. ${ }^{2}$ Although many empirical studies address this issue, the empirical findings regarding options listing around the world are conflicting. As one example, in the U.S. market, the effects of options listing on the underlying individual stocks over the last 30 years are completely different from such effects 30 years ago. ${ }^{3}$ To be specific, for the period before 1980, previous empirical studies find that options listing increased underlying stock prices, decreased volatilities, and decreased price reactions to earnings announcements (Conrad, 1989, Detemple and Jorion, 1990 and Skinner, 1989). However, for the period after 1980, recent studies find the opposite effects (Sorescu, 2000 and Mayhew and Mihov, 2000). There are no plausible explanations for these conflicting findings. Hence, they remain puzzling.

\section{Option Trading}

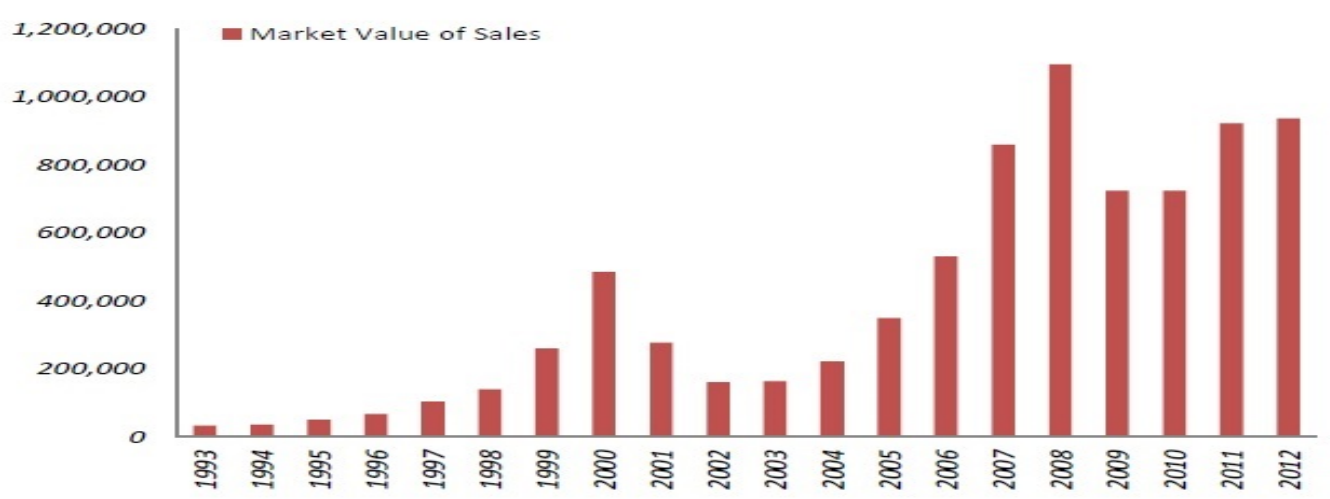

Figure 1: Trading Activity in the U.S. Options Market (in millions of dollars)

To our knowledge, few theoretical studies examine the effects of derivatives on their underlying assets with endogenous information acquisition. Among the few studies, Cao (1999) and Massa (2002) show that introducing derivatives increases the underlying asset's price, decreases volatility and decreases price reactions to earnings announcements. They thus provide explanations to the

\footnotetext{
${ }^{1}$ Data Source: SELECT SEC AND MARKET DATA FISCAL 2013. Data is about all sales of options listed on exchange and excludes options on indexes

${ }^{2}$ After credit crunch of 2007-08, The Dodd-Frank Wall Street Reform and Consumer Protection Act, which was signed into federal law on July 21, 2010, is considered to bring most significant changes to financial regulation on derivative markets including interest rate option and currency option. Then there is a hot debate on whether Dodd-Frank is enough to prevent systemic risk.

${ }^{3}$ Although most empirical studies are about U.S. market, there are some evidences to show that option listing decreases price and increases volatility of underlying individual stocks in developed markets, such as Germany (Heer et al., 1997), while it increases price and decreases volatility in developing markets, such as India (Nair, 2008).
} 
empirical findings regarding options listing in U.S. before 1980, but offer little guidance on the empirical findings after 1980 .

In this paper, we exam the effect of an options market on investors' incentive to collect private information in a rational expectation equilibrium model. Following the canonical frameworks of Grossman and Stiglitz (1980) and Hellwig (1980), our economy has one risky asset and one risk-free asset. We then introduce an options market that includes a set of call and put options on the risky asset. Investors choose whether to acquire private information before trading. We compare investors' information acquisition decisions before and after the options market opens. More important, we examine the effect of the options market on the underlying asset through its effect on information acquisition.

We find that introducing an options market has two effects on information acquisition. First, options act as substitutes for private information because both options and private information are valuable in reducing risk. ${ }^{4}$ Investors can hence choose whether to acquire information or use options. Thus, introducing an options market negatively affects investors' incentive to acquire information. This first effect is a substitution effect. Second, options are valuable for investors with imprecise information because such investors face high uncertainty. Informed investors therefore have less need for options than uninformed investors. In an equilibrium where the net supply of options is zero, informed investors earn profits by selling options to uninformed investors. Thus, introducing an options market positively affects investors' incentive to acquire information. This second effect is a profit-making effect. The effect of an options market on information acquisition depends on these two effects. When the information acquisition cost is low, the population of informed investors is high, which leads to a lower demand than supply for options. Consequently, the option prices are low, affording informed investors little opportunity to cover the information acquisition cost by selling options. Meanwhile, investors can use cheap options instead of private information to reduce their risk. Therefore, the two effects work in conjunction to decrease investors' incentive to acquire information. The price of the underlying asset then becomes less informative, resulting in a lower price and higher volatility. With less precise private information, investors must rely more on public information, which generates greater price reactions to earnings announcements. By contrast, when the information acquisition cost is sufficiently high, the population of informed investors is low, which leads to a higher demand than supply for options. Consequently, option prices are high, offering informed investors large opportunity to cover the information acquisition cost by selling options. Therefore, the profitmaking effect exerts a larger counteracting force against the substitution effect, leading to opposite effects on information acquisition and asset pricing. Moreover, we show that our mechanism is

\footnotetext{
${ }^{4}$ The intuition can be shown from the Black-Scholes model, which shows that the option price increases with underlying asset value's volatility
} 
robust for other derivatives, such as straddles.

We also find that the effect of an options market on information acquisition depends on the precision of public information. When public information is precise, the population of informed investors is low before the options market opens. Consequently, the demand for options is larger than the supply, affording informed investors large opportunity to earn profits. Thus, introducing an options market increases investors' incentive to collect private information, increases the price of the underlying asset, decreases volatility, and decreases price reactions to earnings announcements. When public information is imprecise, the population of informed investors is high, leading to low option prices. Consequently, the opposite effects on the underlying asset arise.

Moreover, we show that the introduction of additional trading rounds has similar effects to the introduction of an options market. Brennan and Cao (1996) argues that additional trading rounds, which can be interpreted as after-hour or round-the-clock trading, can improve the welfare of all investors because both additional trading rounds and derivatives markets increase risk-sharing opportunities. However, their effect on information acquisition is unclear. Following Brennan and Cao (1996), we extend our model to consider multiple rounds of trading, where each round provides a new public information. Complementing to their study, we find that additional trading rounds produce asymmetric benefits for different groups, which leads to non-monotonic effects on information acquisition. Because risk sharing occurs between different groups, the relative benefits depend on the competition within each group. For example, when the population of informed investors is high, the competition within the group of informed investors is high. Consequently, the benefit from more risk-sharing opportunities is lower for informed investors than for uninformed investors, which reduces the marginal benefit of information. Thus, when the population of informed investors is high because of the low information acquisition cost, introducing additional trading rounds decreases investors' incentive to acquire information, lowering the asset price and increasing volatility. When the information acquisition cost is high, the opposite effects arise.

Our results indicate that the effects of options listing on the underlying assets depend on the information acquisition cost. Our results therefore provide a unified explanation for the conflicting findings regarding the effects of options listing on underlying individual stocks in the U.S. market and international markets. For example, before 1980 when information acquisition cost is conventionally believed to have been high, our results are consistent with the findings in U.S. that options listing increased underlying stock prices (Branch and Finnerty, 1981, Conrad, 1989 and Detemple and Jorion, 1990), decreased volatilities (Hayes and Tennenhaum, 1979, Skinner, 1989, Conrad, 1989, Ho, 1993 and Damodaran and Lim, 1991), and decreased price reactions to earnings announcements (Jennings and Starks, 1986, Skinner, 1990, Damodaran and Lim, 1991 and Ho, 1993$).{ }^{5}$ After 1980 when information acquisition cost is conventionally believed to be

\footnotetext{
${ }^{5}$ Information acquisition cost is lower after 1980 than that before 1980 because the technology is developed and
} 
low, our results are consistent with the opposite empirical findings that options listings decrease underlying stock prices (Sorescu, 2000 and Mayhew and Mihov, 2000), increase volatilities(Bollen, 1998 and Mayhew and Mihov, 2000), and increase price reactions to earnings announcements (Mendenhall and Fehrs, 1999). Meanwhile, our results could also explain the empirical findings in international markets. For example, according to the conventional belief, the information acquisition cost is high in emerging markets, but low in developed markets. Our results are consistent with existing empirical findings: options listings increase the underlying stock prices and decrease volatilities in emerging markets, such as India (Nair, 2008), but decrease the underlying stock prices and increase volatilities in some developed markets, such as Germany (Heer et al., 1997).

Related Literature Our study is related to several strands of literature. First, this study is associated with theoretical studies on the effects of derivatives on underlying assets, such as those by Grossman (1988), Biais and Hillion (1994), Huang and Wang (1997), Cao (1999) and Massa (2002). Cao (1999) and Massa (2002) are the most relevant to the present study, as they examine the effects of derivatives on information acquisition. Both authors find that introducing derivatives increases the prices of underlying assets, decreases price volatilities and decreases the price reactions to earnings announcements. The derivative examined in Massa (2002) conveys new information, which leads to increased price informativeness. By contrast, the derivatives examined in Cao (1999) and our study do not convey any additional information by themselves. However, Cao (1999) finds only a profit-making effect for the examined derivatives. Specifically, the author considers two groups of investors: inactive investors, who are unable to acquire information, and active investors, who determine the precision of private information. The author concludes that introducing derivatives increases the information precisions for active investors. However, in his model, the inactive investors are not able to acquire information, which hinders the substitution effect. Thus, derivatives have monotonic effects on information acquisition. In contrast to Cao (1999) and Massa (2002), we find that derivatives have two effects on information acquisitions: substitution effect and profit-making effect. More important, we find that the effects of derivatives on information acquisition and the underlying asset depend on the information acquisition cost and the precision of public information.

Meanwhile, our approach takes a first step to model an explicit options market in an economy with information asymmetry. AlthoughCao (1999) studies the effects of derivatives on their underlying assets, the derivatives in the proposed model take reduced forms and they are interpreted as straddles. The most relevant paper to ours is by Cao and Ou-Yang (2009), who also model a set of call and put options. However, the authors only conduct the analysis in an economy with heterogeneous beliefs without any implications for information acquisition.

it is easier for investors to search for information. 
Our work is also related to the large strand of literature on financial innovation (Allen and Gale, 1994, Brock, Hommes and Wagener, 2009, Dow, 1998, Dieckmann, 2011, Duffie and Rahi, 1995, Simsek, 2013a,b, Weyl, 2007 and Chabakauri, Yuan, Zachariadis, 2014). However, most studies in this literature stream examine the impact of financial innovations without information asymmetry. For example, Brock, Hommes and Wagener (2009), Simsek (2013a) and Simsek (2013b) emphasize the destabilizing effect of financial innovations due to heterogeneous beliefs. The most relevant paper to ours in this body of literature is by Dow (1998), who proposes a hedge-more/bet-more effect in an economy with asymmetric information. The author finds that a new asset induces risk averse arbitrageurs to hedge their positions in the preexisting security, which affects the old market's liquidity. This hedge-more/bet-more effect may have a negative effect on all investors' welfare. However, we show that options do not have a direct effect on the underlying asset, which confirms the findings by Chabakauri, Yuan, Zachariadis (2014). Moreover, we find that options affect the underlying assets through their effects on information acquisition.

The reminder of the paper is organized as follows. We introduce the model setup in Section 2 and solve a model without an options market. In Section 3, we study the effects of an options market on information acquisition and the underlying asset in a static model. Section 4 then extends the static model to a dynamic model. Section 5 discusses more general derivative. Section 6 concludes and discusses our empirical predictions.

\section{Model}

Based on the canonical frameworks with one risky asset and one risk-free asset by Grossman and Stiglitz (1980) and Hellwig (1980), we introduce an options market. Our goal is to compare the equilibrium population of informed investors and asset pricing before and after an options market is introduced into the economy. Before we solve the equilibrium in the economy with the options market, we solve the equilibrium in the economy without the options market in this section.

\section{$2.1 \quad$ Timeline and assets}

There are two periods in our economy, $T=0,1$. There is one risk-free asset and one risky asset. The risk-free asset is in zero supply, and it pays off one unit of a consumption good without uncertainty. The risky asset pays off $D$ and has a positive supply of $\bar{X}$, where $D \sim N\left(\bar{D}, \frac{1}{h}\right)$.

There is an options market in our economy, and the underlying asset is the risky asset. Following Cao and Ou-Yang (2009), we assume that the options market consists of a set of call and put options. The strike price of one specific option is denoted by $G$. The call option with strike price $G$ then has a payoff as $(D-G)^{+}$, whereas the put option with strike price $G$ has a payoff as $(G-D)^{+}$. The net supply of each option is zero. Because of the put-call parity, we can 
only consider call options with positive strike prices and put options with negative strike prices to simplify our analysis. ${ }^{6}$ We assume that informed investor $i$ 's demand for risky asset is $X_{i}$, that his demand for call options with strike prices $G$ to $G+d G$ is $X_{i, C G}$, and that his demand for put options with strike prices $G$ to $G+d G$ is $X_{i, P G}$. Moreover, we assume that the uninformed investors' demand for risky asset is $X_{U}$, that their demand for call options with strike prices $G$ to $G+d G$ is $X_{U, C G}$, and that their demand for put options with strike prices $G$ to $G+d G$ is $X_{U, P G}$. The price of the risky asset is denoted by $P$. The price of a call option with strike price $G$ is $P_{C G}$ and the price of a put option with strike price $G$ is $P_{P G}$. Our model differs from that of Cao and Ou-Yang (2009) in that we introduce an options market into an economy with asymmetric information, whereas they focus on the heterogeneous beliefs.

\subsection{Investors and information acquisition}

There is one continuum of investors. The investors' utility function over the final wealth at $T=1$ follows a standard CARA utility function with risk-averse coefficient $\gamma$ :

$$
-\exp \left(-\gamma W_{1}\right)
$$

where $W_{1}$ is the wealth at $T=1$ and is equal to $W_{0}+X_{i}(D-P)$. Each investor is indexed by $i$, where $i \in[0,1]$. Without a loss of generality, we assume that all investors have zero endowment of the risky asset, and that they have the same initial wealth $W_{0}$. The market opens at $T=0$. For informed investor $i$, he or she has a private signal about the risky asset's payoff before trading at $T=0$ :

$$
S_{i}=D+\epsilon_{i}
$$

where $\epsilon_{i}$ follows normal distribution $N\left(0, \frac{1}{s}\right)$ and is independent of cross investors $\left(\operatorname{corr}\left(\epsilon_{i}, \epsilon_{j}\right)=0\right.$ for $i \neq j$ ). We assume that the precision of private signals that investors acquire is the same. Fruther, investors can only acquire one private signal. If the investors choose to acquire the private signals, then they need to pay a cost $C$, which is called then information acquisition cost. The population of informed investors is denoted by $\omega$, which is endogenous in our economy. At $T=1$, the payoff is realised and all investors consume their total wealth.

In addition to these investors,some noisy traders exist in the market. We assume that the total demand from noisy traders is $n$, which follows normal distribution $N\left(0, \frac{1}{q}\right)$.

\footnotetext{
${ }^{6}$ If we introduce options with all strike prices, our results are robust because call options with negative strike prices are redundant because they can be replicated by put options with negative strike prices and stock.
} 


\subsection{Information acquisition without an options market}

We first derive the equilibrium given the population of informed investors $\omega$ and then solve the equilibrium $\omega$. This section shows that the equilibrium $\omega$ decreases with the information acquisition cost. In the analysis that follows, we compare the equilibrium $\omega$ in the economy with and without an options market. This comparison demonstrates the effect of an options market on the underlying asset pricing through the information acquisition channel.

All of the investors submit their demand conditional on their information sets, and the equilibrium price clears the market. Informed investor $i$ 's information set is $\mathcal{F}_{i}=\left\{S_{i}, P\right\}$, whereas uninformed investors' information set is $\mathcal{F}_{U}=\{P\}$. As shown by Grossman and Stiglitz (1980) and Hellwig (1980), the following linear equilibrium exists:

$$
P=\bar{D}-\frac{\gamma \bar{X}}{B}+\frac{\left(\omega s+\frac{\omega^{2} s^{2} q}{\gamma^{2}}\right)\left(D-\bar{D}+\frac{\gamma}{\omega s} n\right)}{B}
$$

Informed investor $i$ 's demand:

$$
X_{i}=\frac{E\left(D \mid \mathcal{F}_{i}\right)-P}{\gamma \operatorname{Var}\left(D \mid \mathcal{F}_{i}\right)}
$$

Uninformed investors' demand:

$$
X_{U}=\frac{E\left(D \mid \mathcal{F}_{U}\right)-P}{\gamma \operatorname{Var}\left(D \mid \mathcal{F}_{U}\right)}
$$

where

$$
\begin{gathered}
B=h+\omega s+\frac{\omega^{2} s^{2} q}{\gamma^{2}} \\
E\left(D \mid \mathcal{F}_{i}\right)=\bar{D}+\frac{s\left(S_{i}-\bar{D}\right)+\frac{\omega^{2} s^{2} q}{\gamma^{2}}\left(D-\bar{D}+\frac{\gamma}{\omega s} n\right)}{h+s+\frac{\omega^{2} s^{2} q}{\gamma^{2}}} \text { and } \operatorname{Var}\left(D \mid \mathcal{F}_{i}\right)^{-1}=h+s+\frac{\omega^{2} s^{2} q}{\gamma^{2}}, \\
E\left(D \mid \mathcal{F}_{U}\right)=\bar{D}+\frac{\frac{\omega^{2} s^{2} q}{\gamma^{2}}\left(D-\bar{D}+\frac{\gamma}{\omega s} n\right)}{h+\frac{\omega^{2} s^{2} q}{\gamma^{2}}} \text { and } \operatorname{Var}\left(D \mid \mathcal{F}_{U}\right)^{-1}=h+\frac{\omega^{2} s^{2} q}{\gamma^{2}}
\end{gathered}
$$

We substitute the investors' demand into their final wealth and the expected utility of informed investors/uninformed investors is given by (where $U_{I}$ is the informed investors' expected utility, and $U_{U}$ is the uninformed investors' expected utility):

$$
\begin{gathered}
U_{I}=-\exp \left[-\gamma W_{0}-\frac{\bar{X}^{2}}{2 \gamma B^{2} \operatorname{Var}(D-P)}\right] \times \frac{1}{\sqrt{\operatorname{Var}(D-P) B_{i}}}, \\
U_{U}=-\exp \left[-\gamma W_{0}-\frac{\bar{X}^{2}}{2 \gamma B^{2} \operatorname{Var}(D-P)}\right] \times \frac{1}{\sqrt{\operatorname{Var}(D-P) B_{U}}},
\end{gathered}
$$

where

$$
B_{i}=h+s+\frac{\omega^{2} s^{2} q}{\gamma^{2}} \text { and } B_{U}=h+\frac{\omega^{2} s^{2} q}{\gamma^{2}}
$$


The informed investors' utility is clearly higher than the uninformed investors' utility. Thus, the informed investors gain from private information. In the equilibrium, the population of informed investors $\omega$ should render the gain from private information and the $\operatorname{cost} C$ equal. Then, we define the gain from information acquisition $G$ as: ${ }^{7}$

Definition 2.1. The Gain from information acquisition is $G=\left(U_{U} / U_{I}\right)^{2}$
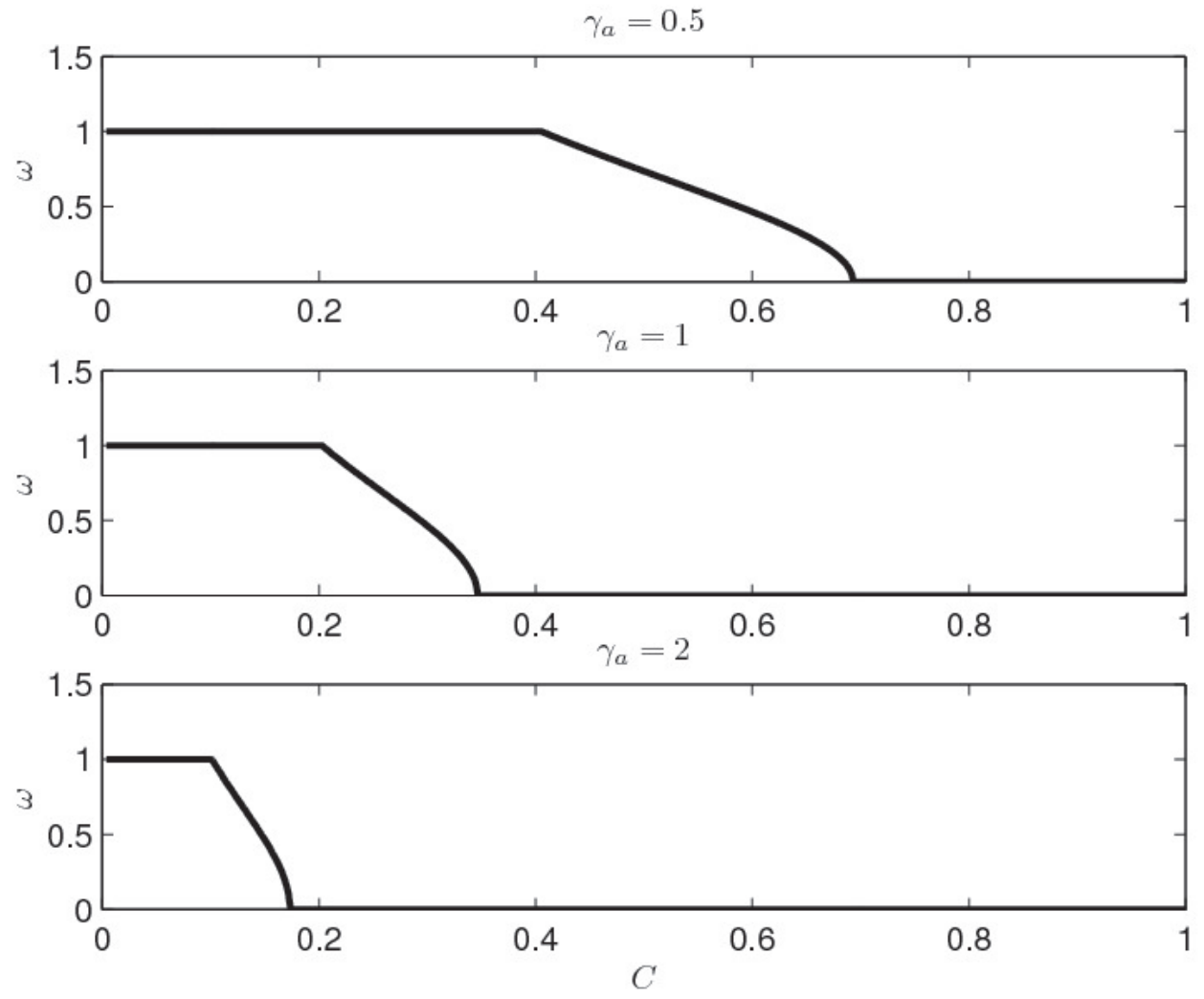

Figure 2: The Relationship between the Population of Informed Investors and the Acquisition Cost

The gain from information acquisition is $\frac{B_{i}}{B_{U}}$. We can therefore show the results regarding $\omega^{*}$ as follows (see Figure 2).

Proposition 2.1. In the equilibrium without an options market, the population of informed investors renders the gain from information acquisition and its cost equal. Then, there are three cases:

Case 1: If $C \geq C_{d 1}$, the equilibrium population of informed investors is $\omega^{*}=0$.

Case 2: If $C_{d 2}<C<C_{d 1}$, the equilibrium population of informed investors is $\omega^{*} \in(0,1)$.

Case 3: If $C \leq C_{d 2}$, the equilibrium population of informed investors is $\omega^{*}=1$.

where $C_{d 1}$ and $C_{d 2}$ are defined as in the Appendix.

\footnotetext{
${ }^{7}$ We set $\mathrm{h}=1, \mathrm{~s}=1$ and $\mathrm{q}=1$ in the Figure 2
} 
Corollary 2.1. When $C_{d 2}<C<C_{d 1}$, $\omega^{*}$ is monotonically decreasing with the information acquisition cost $C$.

Based on the equilibrium population of informed investors, we examine the effect of introducing an options market on $\omega$ and the underlying asset in the following sections. Because we have corner solutions in Case 1 and Case 3, we focus on the Case 2 to conduct the study.

\section{Introduction of an Option Market}

In this section, we analyze the effects an options market on investors' information acquisition decisions and the underlying asset. We study the role of the information acquisition cost in the effects. We first solve a static model with an option markets, and then we extend this static model to a dynamic model in next section. We demonstrate the robustness of the results.

After an options market in introduced, the investors' information sets differ from before the options market is introduced. For informed investor $i$, his or her information set is $\mathcal{F}_{i}=\left\{S_{i}, P, P_{C G}, P_{P G}\right\}$, whereas uninformed investors' information set is $\mathcal{F}_{U}=\left\{P, P_{C G}, P_{P G}\right\}$. Our conjecture is that the underlying risky asset's price is a linear function of fundamental payoff $D$ and the noisy traders' demand $n$. The partially revealing rational expectations equilibrium regarding $P, P_{C G}, P_{P G}$ and the investors' demands is described in the following proposition.

Proposition 3.1. There exists one equilibrium in $T=0$. Equilibrium $P$ and $P_{G}$ are given by:

$$
\begin{gathered}
P=\bar{D}-\frac{\gamma \bar{X}}{B}+\frac{\left(\omega s+\frac{\omega^{2} s^{2} q}{\gamma^{2}}\right)\left(D-\bar{D}+\frac{\gamma}{\omega s} n\right)}{B}, \\
P_{C G}=(P-G) N(\sqrt{B}(P-G))+\frac{1}{\sqrt{B}} \exp \left(-\frac{B(P-G)^{2}}{2}\right), \quad \text { where } G \geqslant 0, \\
P_{P G}=(G-P) N(\sqrt{B}(G-P))+\frac{1}{\sqrt{B}} \exp \left(-\frac{B(G-P)^{2}}{2}\right), \quad \text { where } G<0,
\end{gathered}
$$

Informed investor $i$ 's demands for risky asset is:

$$
X_{i}=\frac{E\left(D \mid \mathcal{F}_{i}\right)-P}{\gamma \operatorname{Var}\left(D \mid \mathcal{F}_{i}\right)}-\frac{\left(B-B_{i}\right)}{\gamma} P
$$

Informed investor i's demands for options is:

$$
X_{i, C G}=\frac{1}{\gamma}\left(B-B_{i}\right) \quad \text { and } \quad X_{i, P G}=\frac{1}{\gamma}\left(B-B_{i}\right)
$$


Uninformed investor's demand for risky asset is:

$$
X_{U}=\frac{E\left(D \mid \mathcal{F}_{U}\right)-P}{\gamma \operatorname{Var}\left(D \mid \mathcal{F}_{U}\right)}-\frac{\left(B-B_{U}\right)}{\gamma} P
$$

Uninformed investor $j$ 's demands for options is:

$$
X_{U, C G}=\frac{1}{\gamma}\left(B-B_{U}\right) \quad \text { and } \quad X_{U, P G}=\frac{1}{\gamma}\left(B-B_{U}\right)
$$

where $B=h+\omega s+\frac{\omega^{2} s^{2} q}{\gamma^{2}}, B_{i}=h+s+\frac{\omega^{2} s^{2} q}{\gamma^{2}}$ and $B_{U}=h+\frac{\omega^{2} s^{2} q}{\gamma^{2}}$.

Several interesting features of Proposition 3.1 are notable. First, the option prices are functions of the price of the underlying asset, and they do not convey any additional information, in contrast to the derivative in Massa (2002), which carries additional information by itself. Because options do not carry additional information, we can isolate the effect proposed by Massa (2002) based on this feature. Second, $B_{U}$ and $B_{i}$ represent information precisions of information for uninformed and informed investors respectively, whereas $B$ is the precision of the aggregate information. Following the intuition that the value of options depends on investors' conditional volatility regarding the underlying asset's payoff, informed investors' demand for options is lower than uninformed investors's demand. In the equilibrium where the net supply of each option is zero, informed investors are on the short side of options. Thus, introducing an options market provides an opportunity for informed investors to profit from selling options. Following the same mechanism, the third feature is that the aggregate option prices decrease with the precision of aggregate information $B$, which is shown in the following Lemma 3.1. The analysis implies that options have a similar effect to information in reducing risk. ${ }^{8}$

Lemma 3.1. The aggregate price of options is $\int_{0}^{\infty} P_{C G} d G+\int_{-\infty}^{0} P_{P G} d G=\frac{1}{2}\left(\frac{1}{B}+P^{2}\right)$.

In line with Grossman and Stiglitz (1980), the equilibrium population of informed investors renders the expected utility of informed and uninformed investors equal. Before we perform the comparisons, we must show that there is a unique equilibrium in information acquisition with an options market. Otherwise, showing the effects of options would be difficult. To demonstrate the existence of a unique equilibrium, we only need to show that the gain from information decreases with the population of informed investors $\omega$, which can be shown as follows. ${ }^{9}$

Lemma 3.2. The gain from information $G$ with an option market is $\exp \left(\frac{s}{B}\right)$.

\footnotetext{
${ }^{8}$ The aggregate payoff of options is: $D^{2}=2 \int_{0}^{\infty}(D-G)^{+} d G+2 \int_{-\infty}^{0}(G-D)^{+} d G$.

${ }^{9}$ We set $\mathrm{h}=1, \mathrm{~s}=1, \mathrm{q}=1$ and $\gamma=0.5$ in the Figure 3
} 


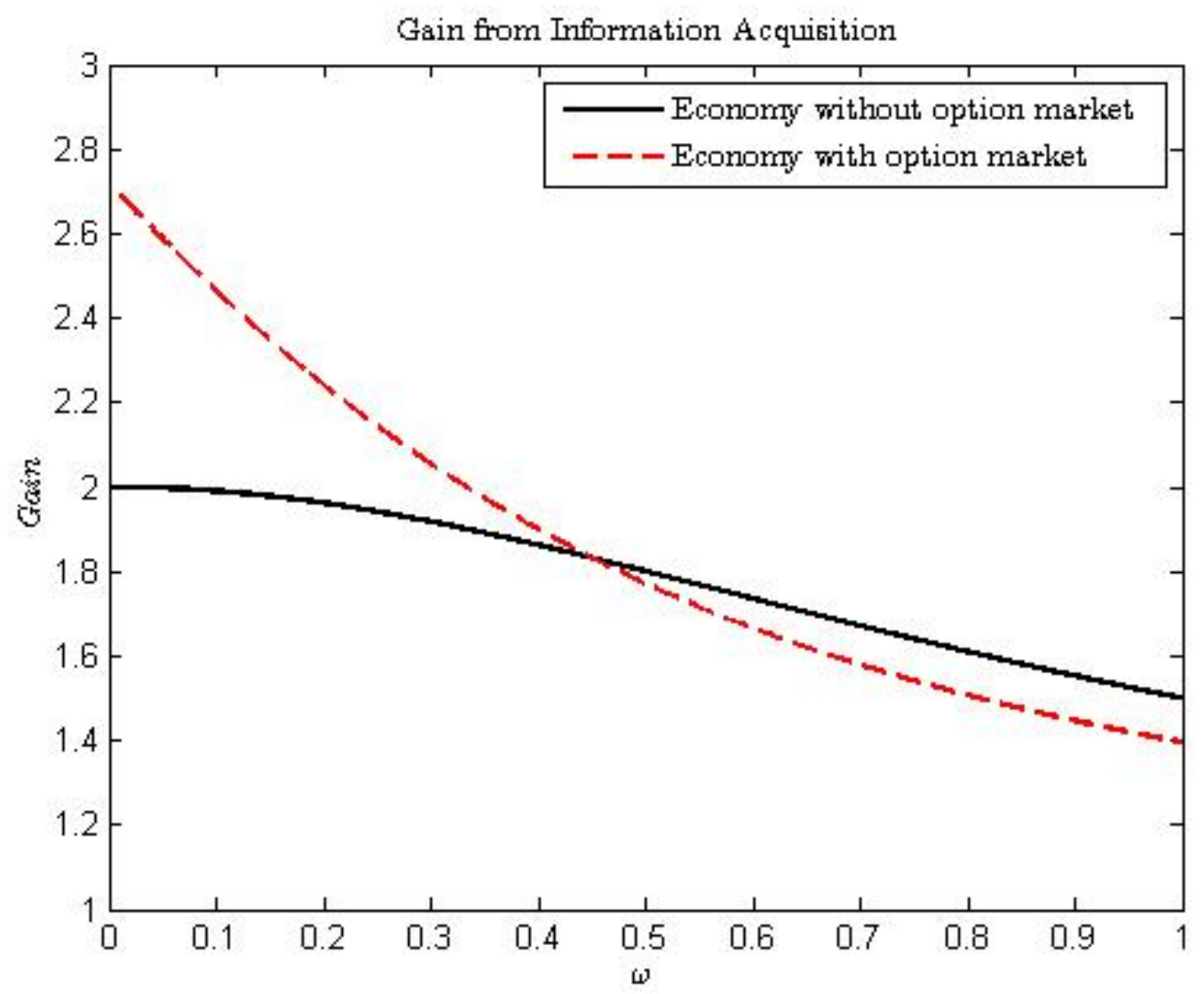

Figure 3: Gain from Information Acquisition: Effect of an Options Market

The gain from information clearly decreases with the population of informed investors, which implies that a unique solution exists for information acquisition. However, whether the equilibrium population of informed investors in the economy with options is higher than that without options is unclear. Because the information acquisition cost is constant, the equilibrium population of informed investors is higher in the economy with options if $\exp \left(\frac{s}{B}\right)$ is higher than $\frac{B_{i}}{B_{U}}$, and vice versa. Figure 3 shows that when the population of informed investors is zero, $\exp \left(\frac{s}{B}\right)$ is higher $\frac{B_{i}}{B_{U}}$. This result indicates that when the population of informed investors is close to 0 , the gain from information is higher in the economy with options than in the economy without options. Thus, introducing an options market increases investors' incentive to acquire information. When the population of informed investors is $1, \exp \left(\frac{s}{B}\right)$ is smaller than $\frac{B_{i}}{B_{U}}$. This result indicates that when the population of informed investors is close to 1 , the gain from information is lower in the economy with options than in the economy without options. Thus, introducing an option market decreases investors' incentive to acquire information. ${ }^{10}$ Because the population of informed investors depends on the information acquisition cost, we obtain the following formal results with

${ }^{10}$ The analysis here uses the relations: $\frac{x}{1+x}<\ln (1+x)<x$ for $x>0$ 
regard to the effect of options on information acquisition.

Proposition 3.2. When $C \in\left(C_{d 2}, C_{d 1}\right)$, cutoffs $C_{3}$ and $C_{4}$ exists, which satisfies the following conditions:

(1) when $C>C_{4}$, introducing an options market increases the population of informed investors.

(2) when $C<C_{3}$, introducing an options market decreases the population of informed investors.

where $C_{3}$ and $C_{4}$ are defined as in the Appendix and $C_{3}<C_{4}$.
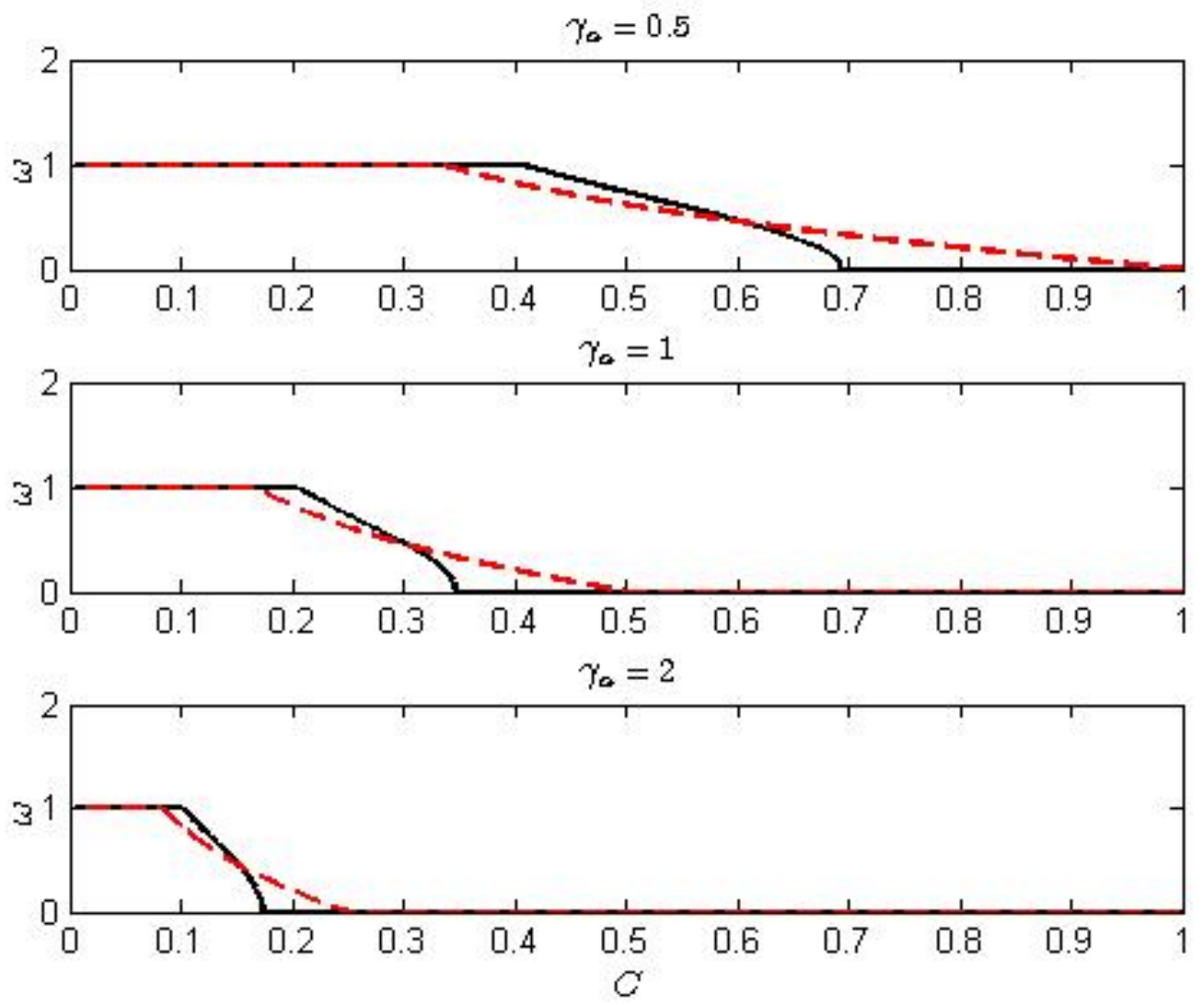

Figure 4: The Relationship Between Population of Informed Investors and Acquisition Cost: Effect of Option Market

Proposition 3.2(see Figure 4) shows that introducing an options market increases investors' incentive to acquire information when the information acquisition cost is high and decreases investors' incentive to acquire information when the information acquisition cost is low. ${ }^{11}$ From the Proposition 3.1, we know that the supply of options is higher than the demand when the

\footnotetext{
${ }^{11}$ We set $\mathrm{h}=1, \mathrm{~s}=1, \mathrm{q}=1$ in the Figure 4
} 
population of informed investors is high. Meanwhile, as shown in Lemma 3.1, the aggregate option prices tend to be low. The selling profits of informed investors in the options markets clearly depend on both the demand per supplier and the option prices. Thus, the profits from selling options are low for informed investors, and they will not cover the information acquisition cost when the demand is too low. Moreover, investors could use cheap options instead of information to hedge their portfolios risk, which implies that introducing an options market decreases investors' incentive to acquire information. By contrast, the supply of options is lower than then demand when the population of informed investors is low, leading to high aggregate option prices. In particular, when the demand per supplier is sufficiently large, information investors' profits from selling options will cover the information acquisition cost, which implies that introducing an options market increases investors' incentive to acquire information. Given its effect on information acquisition, the options market has a direct effect on the price informativeness. To show the effect of options on price informativeness, we define price informative as follows.

DeFInITION 3.1. The price informativeness $I: I=\frac{1}{\operatorname{Var}(D \mid P)}$.

Because the option prices do not convey any additional information, the above definition of $I$ captures all of the information that is conveyed by the market. Thus we can conveniently show the effect of options on price informativeness. Price informativeness is clearly $\frac{\omega^{2} s^{2} q}{\gamma^{2}}$, and it increases with the population of informed investors. Because introducing an options market affects the population of informed investors, we obtain the following formal results regarding price informativeness.

Proposition 3.3. When $C \in\left(C_{d 2}, C_{d 1}\right)$,

(1) when $C>C_{4}$, introducing an options market increases price informativeness $I$.

(2) when $C<C_{3}$, introducing an options market decreases price informativeness $I$.

where $C_{3}$ and $C_{4}$ are defined as in the Appendix and $C_{3}<C_{4}$.

In addition to the effect of options on information acquisition, we also examine their effects on the price and volatility of the underlying asset. Because uncertainty exists regarding the asset payoff, the price is discounted. The expected difference between the asset payoff and price is called the cost of capital: $E(D-P)$. The cost of capital $E(D-P)$ decreases with the expected asset price. Thus the result for expected asset price is equivalent to the analysis on the cost of capital. The expected asset price is given by:

$$
E(P)=\bar{D}-\frac{\gamma \bar{X}}{B}
$$


and the volatility $V(D-P)$ is given by:

$$
\operatorname{Var}(D-P)=\frac{1}{B}+\frac{\omega s+\gamma^{2} q^{-1}}{B^{2}}
$$

The expected asset price clearly increases with $B$, and the volatility decreases with $B$. Thus, we have the following results:

Proposition 3.4. When $C \in\left(C_{d 2}, C_{d 1}\right)$,

(1) when $C>C_{4}$, introducing an options market increases the expected asset price and decreases the price change volatility.

(2) when $C<C_{3}$, introducing an options market decreases the expected asset price and increases the price change volatility.

These results arise from the effect of options on information acquisition. When the information acquisition cost is high, introducing an options market increases the population of informed investors. Because informed investors have information that is precise, they trade more aggressively, and they are more willing to absorb noisy supply, which indicates that the demand for the underlying asset increases, along with a higher expected price level. The price then becomes less sensitive to noisy supply because increased price informativeness. Consequently, the nonfundamental volatility decreases, leading to decreased total volatility. When the information acquisition cost is low, a similar mechanism generates the opposite results. In contrast to the findings of Cao (1999) and Massa (2002), these results imply that the information acquisition cost plays an important role in the effect of options on asset pricing.

We also examine the effect of the information acquisition cost on the trading volume of options. The trading volume in the options market is calculated as follows:

Lemma 3.3. The trading volume in option market $V_{O}=\frac{1}{\gamma}\left(\int_{0}^{\omega}\left|\left(B_{i}-B\right)\right| d i+(1-\omega)\left|B-B_{U}\right|\right)=$ $\frac{2 \omega(1-\omega) s}{\gamma}$.

Because the short side comes from informed investors and long side comes from uninformed investors in the options market, intuitively, the trading volume is zero when all investors are informed or uninformed. When the information acquisition cost increases from zero, the population of uninformed investors increases, which enhances the trading between the different groups. When the information acquisition cost is sufficiently high, the population of uninformed investors is high, which makes total total trading volume vanish.

Proposition 3.5. The trading volume in the options market exhibits a hump shape as a function of the information acquisition cost: $V_{o}$ decreases with the information acquisition cost when $C$ is higher than $C_{M}$, and increases with the information acquisition cost when $C$ is lower than $C_{M}$, where $C_{M}$ is defined as in the Appendix. 


\section{Dynamic Model with an Options Market}

This section aims to demonstrate the robustness of the results in Section 3 are robust. Moreover, the dynamic model is helpful for studying the effect of an options market on the price reaction to public information.

\subsection{Dynamic model without an Options Market}

To model dynamic trading, following Brennan and Cao (1996), we assume that there is an approximate continuous trading time from $T=0$ to $T=1$. The trading ends at $t$, where $t$ is between $T=0$ and $T=1$. To make the model tractable, we assume that investors can trade only once in a small time interval $z$, which means that trading occurs only in the time intervals $[0, z),[z, 2 z),[3 z, 4 z) \ldots .[(K-1) z, K z)$, where $K$ is the largest integer satisfying $K z \leq t .{ }^{12}$ We index the interval $[(j-1) z, j z)$ by trading round $j$. Before each trading round $j$, a public signal is released. The public signal before trading round $j$ is

$$
S_{c, j}=D+\epsilon_{c, j}
$$

where $j=1,2 \ldots K$ and $\epsilon_{c, j}$ follows normal distribution $N\left(0, \frac{1}{c_{j} z}\right) . \epsilon_{c, j}$ is independent from trading rounds and is independent from noise in investors' private signal. We assume that $z$ tends to be zero throughout our analysis. This assumption guarantees that the public information flow is sufficiently smooth and that the price change volatility tends to be zero between two consecutive trading rounds when the time interval is close to zero. We further assume that the precision of the aggregate public information until trading round $j$ is $F_{j}$, where $F_{j}=\sum_{k=1}^{k=j} c_{k} z$. Therefore, $F_{K}$ is the aggregate precision of public information in this dynamic model. Furthermore, to simplify the analysis, we assume that there are no additional noisy traders after the initial trading round. 13

Investors submit their demand schedules conditional on their information sets. The information set for informed investor $i$ in trading session $j$ is $\mathcal{F}_{i, j}=\left\{S_{i}, S_{c, k}, P_{k}, k=1,2 \ldots . j\right\}$, whereas the information set for uninformed investors in trading session $j$ is $\mathcal{F}_{U, j}=\left\{S_{c, k}, P_{k}, k=1,2 \ldots . j\right\}$. We assume that investor $i$ submits optimal demand schedule $X_{i, j}$ in trading round $j$. Our conjecture is that the risky asset's price function is a linear function of fundamental payoff $D$, the noisy traders' demand $n$, and public signals. The partially revealing rational expectations equilibrium is described in the following proposition.

\footnotetext{
${ }^{12}$ Here, $z$ is similar to $d t$ in continuous-time model and it captures the feature of fast trading in practice. When $z$ approximates to be zero, this model converges to the continuous-time model in Brennan and Cao (1996)

${ }^{13}$ Without additional noise traders, it is possible that there are two equilibria (Brennan and Cao, 1996). As argued by Brennan and Cao (1996), one of the equilibria is fully revealing equilibrium and investors make portfolio choices neither conditional on price nor private information, which is not appealing.
} 
Proposition 4.1. Given the population of informed investors $\omega$, one partially revealing rational expectations equilibrium exists, where investors' demand schedule, investors' beliefs and equilibrium prices are given by:

$$
P_{j}=\bar{D}-\frac{\bar{X}}{B_{j}}+\frac{\left(\omega s+\frac{\omega^{2} s^{2} q}{\gamma^{2}}\right)\left(D-\bar{D}+\frac{\gamma}{\omega s} n\right)+\sum_{k=1}^{j} c_{k} z\left(S_{c, k}-\bar{D}\right)}{B_{j}},
$$

where $j=1,2 \ldots K, K+1, \ldots L$.

Informed investors' demand is:

$$
X_{i, j}=\frac{E\left(D \mid \mathcal{F}_{i, j}\right)-P_{j}}{\gamma \operatorname{Var}\left(D \mid \mathcal{F}_{i, j}\right)}
$$

where

$$
\begin{gathered}
E\left(D \mid \mathcal{F}_{i, j}\right)=\bar{D}+\frac{s\left(D-\bar{D}+\epsilon_{i}\right)+\frac{\omega^{2} s^{2} q}{\gamma^{2}}\left(D-\bar{D}+\frac{\gamma}{\omega s} n\right)+\sum_{k=1}^{j} c_{k} z\left(S_{c, k}-\bar{D}\right)}{h+s+\frac{\omega^{2} s^{2} q}{\gamma^{2}}+\sum_{k=1}^{j} c_{k} z}, \\
\operatorname{Var}\left(D \mid \mathcal{F}_{i, j}\right)=\frac{1}{h+s+\frac{\omega^{2} s^{2} q}{\gamma^{2}}+\sum_{k=1}^{j} c_{k} z},
\end{gathered}
$$

Uninformed investors' demand is:

$$
X_{U, j}=\frac{E\left(D \mid \mathcal{F}_{U, j}\right)-P_{j}}{\gamma \operatorname{Var}\left(D \mid \mathcal{F}_{U, j}\right)}
$$

where

$$
\begin{gathered}
E\left(D \mid \mathcal{F}_{U, j}\right)=\bar{D}+\frac{\frac{\omega^{2} s^{2} q}{\gamma^{2}}\left(D-\bar{D}+\frac{\gamma}{\omega s} n\right)+\sum_{k=1}^{j} c_{k} z\left(S_{c, k}-\bar{D}\right)}{h+\frac{\omega^{2} s^{2} q}{\gamma^{2}}+\sum_{k=1}^{j} c_{k} z} \\
\operatorname{Var}\left(D \mid \mathcal{F}_{U, j}\right)=\frac{1}{h+\frac{\omega^{2} s^{2} q}{\gamma^{2}}+\sum_{k=1}^{j} c_{k} z}
\end{gathered}
$$

and

$$
B_{j}=h+\omega s+\frac{\omega^{2} s^{2} q}{\gamma^{2}}+\sum_{k=1}^{j} c_{k} z
$$

Proposition 4.1 shows that the prices only reveal information through $D-\bar{D}+\frac{\gamma}{\omega s} n$, and that the investors behave myopically because there are no additional noisy traders. The expected utilities of informed and uninformed investors are shown in the following Lemma 4.1.

LEMma 4.1. The expected utility of informed investors in the economy with $K$ trading rounds is given by 


$$
U_{I}=-\frac{1}{\sqrt{\operatorname{Var}\left(D-P_{1}\right) B_{i, 1}}} \exp \left[-\gamma W_{0}+\gamma C-\frac{\gamma \bar{X}^{2}}{2 B_{0}^{2} \operatorname{Var}\left(D-P_{0}\right)}\right] \times \prod_{j=2}^{j=K} \frac{1}{\sqrt{1+\frac{c_{j} z\left(B_{j}-B_{i, j}\right)^{2}}{B_{i, j-1} B_{j}^{2}}}}
$$

and the expected utility of uninformed investors is given by

$$
U_{U}=-\frac{1}{\sqrt{\operatorname{Var}\left(D-P_{1}\right) B_{U, 1}}} \exp \left[-\gamma W_{0}-\frac{\gamma \bar{X}^{2}}{2 B_{0}^{2} \operatorname{Var}\left(D-P_{0}\right)}\right] \times \prod_{j=2}^{j=K} \frac{1}{\sqrt{1+\frac{c_{j} z\left(B_{j}-B_{U, j}\right)^{2}}{B_{U, j-1} B_{j}^{2}}}}
$$

where $B_{i, j}=h+s+\frac{\omega^{2} s^{2} q}{\gamma^{2}}+\sum_{k=1}^{j} c_{k} z, B_{U, j}=h+\frac{\omega^{2} s^{2} q}{\gamma^{2}}+\sum_{k=1}^{j} c_{k} z$ and $B_{j}$ is defined as above.

The gain from information $G$ is obviously $\frac{B_{i, 1}}{B_{U, 1}} \prod_{j=2}^{j=N} \frac{1+\frac{c_{j} z\left(B_{j}-B_{i, j}\right)^{2}}{B_{i, j-1} B_{j}^{2}}}{1+\frac{c_{j} z\left(B_{j}-B_{U, j}\right)^{2}}{B_{U, j-1} B_{j}^{2}}}$, where $\frac{1+\frac{c_{j} z\left(B_{j}-B_{i, j}\right)^{2}}{B_{i, j-1} B_{j}^{2}}}{1+\frac{c_{j} z\left(B_{j}-B_{U, j}\right)^{2}}{B_{U, j-1} B_{j}^{2}}}$ is the additional gain generated by trading round $j$. To provide a further comparison, we must show that there is a unique equilibrium of information acquisition. Thus, we must show whether the gain from information decreases with the population of informed investors. We obtain the following result regarding information acquisition:

Proposition 4.2. The gain from information $G$ decreases with the population of informed investors $\omega$.

Proposition 4.2 shows that a unique equilibrium exists. Further, the equilibrium population of informed investors decreases with the information acquisition cost, which is shown below.

COROLlary 4.1. In an economy with $K$ trading rounds, the population of informed investors renders the gain from information and the information acquisition cost equal. There are three cases:

Case 1: If $C \geq C_{1}$, the equilibrium population of informed investors $\omega^{*}=0$.

Case 2: If $C_{2}<C<C_{1}$, the equilibrium population of informed investors $\omega^{*} \in(0,1)$.

Case 3: If $C \leq C_{2}$, the equilibrium population of informed investors $\omega^{*}=1$.

where $C_{1}$ and $C_{2}$ are defined as in the Appendix.

Corollary 4.2. When $C_{2}<C<C_{1}$, $\omega^{*}$ decreases with the information acquisition cost $C$.

Given the information acquisition cost $C$, we show how the precision of public information $F_{K}$ affects the equilibrium population of informed investors $\omega$ in the following results. 
COROLlary 4.3. In an economy with $K$ trading rounds, the population of informed investors renders the gain from information and the information acquisition cost equal. There are three cases:

Case 1: If $F_{K} \geq F_{1}$, the equilibrium population of informed investors $\omega^{*}=0$.

Case 2: If $F_{2}<F_{K}<F_{1}$, the equilibrium population of informed investors $\omega^{*} \in(0,1)$.

Case 3: If $F_{K} \leq F_{2}$, the equilibrium population of informed investors $\omega^{*}=1$.

where $F_{1}$ and $F_{2}$ are defined in the Appendix.

Corollary 4.4. When $F_{2}<F_{K}<F_{1}$, $\omega^{*}$ decreases with the public information precision $F_{k}$.

Corollary 4.3 intuitively indicates that investors' incentive to acquire private information decreases with the precision of public information owing to the decreasing marginal benefit of information. Because there are corner solutions in Case 1 and Case 3, we focus on the Case 2 to perform the analysis regarding the public information.

\subsection{Dynamic model with an options market}

In this section, we solve a dynamic model with an options market to demonstrate that the robustness of the results regarding the effects of options on information acquisition and the underlying asset from the static model. Furthermore, we show the effect of an options market on price reactions to public information.

We introduce an options market, that consists of a section of call and put options, as in Section 3. Let $P_{k}$ be the risky asset's price in trading round $k, P_{C G, k}$ be the price for a call option with strike price $G$, and $P_{P G, k}$ be the price for a put option with strike price $G$. The information set for For informed investor $i$ in trading round $j$ is $\mathcal{F}_{i, j}=\left\{S_{i}, S_{c, k}, P_{k}, P_{C G, k}, P_{P G, k}\right.$, $k=1,2 \ldots j\}$, whereas the information set for uninformed investors in trading round $j$ is $\mathcal{F}_{U, j}=$ $\left\{S_{c, k}, P_{k}, P_{C G, k}, P_{P G, k}, k=1,2 \ldots j\right\}$. We assume that investor $i$ submits optimal demand schedule $X_{i, j}$ for the risky asset, $X_{i, C G, j}$ for call option with strike price $G$, and $X_{i, P G, j}$ for put option with strike price $G$ in trading round $j$. Our conjecture is that the underlying asset's price function is a linear function of fundamental payoff $D$, the noisy trader $n$, and public signals. The partially revealing rational expectations equilibrium is described in the following proposition.

Proposition 4.3. Given the population of informed investors $\omega$, one partially revealing rational expectations equilibrium exists, where investors' demand schedule, investors' beliefs and equilibrium prices are given by:

$$
P_{j}=\bar{D}-\frac{\gamma \bar{X}}{B_{j}}+\frac{\left(\omega s+\frac{\omega^{2} s^{2} q}{\gamma^{2}}\right)\left(D-\bar{D}+\frac{\gamma}{\omega s} n\right)+\sum_{k=1}^{j} c_{k} z\left(S_{c, k}-\bar{D}\right)}{B_{j}},
$$




$$
\begin{array}{ll}
P_{C G, j}=\left(P_{j}-G\right) N\left(\sqrt{B_{j}}\left(P_{j}-G\right)\right)+\frac{1}{\sqrt{B_{j}}} \exp \left(-\frac{B_{j}\left(P_{j}-G\right)^{2}}{2}\right) \quad \text { where } G \geqslant 0, \\
P_{P G, j}=\left(G-P_{j}\right) N\left(\sqrt{B_{j}}\left(G-P_{j}\right)\right)+\frac{1}{\sqrt{B_{j}}} \exp \left(-\frac{B_{j}\left(G-P_{j}\right)^{2}}{2}\right) \quad \text { where } G<0,
\end{array}
$$

where $j=1,2 \ldots . K$.

Informed investors' demand for the underlying asset is:

$$
X_{i, j}=\frac{E\left(D \mid \mathcal{F}_{i, j}\right)-P_{j}}{\gamma \operatorname{Var}\left(D \mid \mathcal{F}_{i, j}\right)}-\frac{\left(B_{j}-B_{i, j}\right)}{\gamma} P_{j}
$$

Informed investors' demand for options is

$$
X_{i, C G, j}=\frac{1}{2 \gamma}\left(B_{j}-B_{i, j}\right) \quad \text { and } \quad X_{i, P G, j}=\frac{1}{2 \gamma}\left(B_{j}-B_{i, j}\right)
$$

Uninformed investors' demand for the underlying asset is:

$$
X_{U, j}=\frac{E\left(D \mid \mathcal{F}_{U, j}\right)-P_{j}}{\gamma \operatorname{Var}\left(D \mid \mathcal{F}_{U, j}\right)}-\frac{\left(B_{j}-B_{U, j}\right)}{\gamma} P_{j}
$$

Uninformed investors' demand for options is

$$
X_{U, C G, j}=\frac{1}{2 \gamma}\left(B_{j}-B_{U, j}\right) \quad \text { and } \quad X_{U, P G, j}=\frac{1}{2 \gamma}\left(B_{j}-B_{U, j}\right)
$$

where $B_{j}=\omega B_{i, j}+(1-\omega) B_{U, j}, B_{i, j}=h+s+\frac{\omega^{2} s^{2} q}{\gamma^{2}}+\sum_{k=1}^{j} c_{k} z$ and $B_{U, j}=h+\frac{\omega^{2} s^{2} q}{\gamma^{2}}+\sum_{k=1}^{j} c_{k} z$

Proposition 4.3 shows that investors' optimal demands for the underlying asset and options are similar to that found in the static model. An interesting finding is that option prices only depend on the price of the underlying asset, and that they do not convey any additional information. Regarding investors' utility, we obtain the following lemma

Lemma 4.2. Informed investor $i$ 's expected utility in trading round $j$ is

$$
E V_{i, j}=-\frac{1}{\sqrt{\frac{B_{j}}{B_{i, j}}}} E\left\{\exp \left[-\gamma W_{i, j}-\frac{\left[E\left(D \mid \mathcal{F}_{i, j+1}\right)-P_{j+1}\right]^{2}}{2 \gamma \operatorname{Var}\left(D \mid \mathcal{F}_{i, j+1}\right)}+\frac{B_{j}-B_{i, j}}{2} \frac{1}{B_{j}}\right]\right\}
$$

and uninformed investors' expected utility in trading round $j$ is:

$$
E V_{U, j}=-\frac{1}{\sqrt{\frac{B_{j}}{B_{U, j}}}} E\left\{\exp \left[-\gamma W_{U, j}-\frac{\left[E\left(D \mid \mathcal{F}_{U, j+1}\right)-P_{j+1}\right]^{2}}{2 \gamma \operatorname{Var}\left(D \mid \mathcal{F}_{U, j+1}\right)}+\frac{B_{j}-B_{U, j}}{2} \frac{1}{B_{j}}\right]\right\}
$$

Lemma 4.2 shows that the gain from information is $\exp \left(\frac{s}{B}\right)$, where $B=h+\omega s+\frac{\omega^{2} s^{2} q}{\gamma^{2}}$. Further, 
this gain decreases with the population of informed investors. Thus, a unique interior solution exists to render the gain from information and the cost equal. To conduct the analysis over the expected asset price and price change volatility, we know that the expected price is given by

$$
E\left(P_{j}\right)=\bar{D}-\frac{\gamma \bar{X}}{B_{j}}
$$

The price change volatility is given by

$$
\operatorname{Var}\left(P_{j+1}-P_{j}\right)=\frac{1}{B_{j}}-\frac{1}{B_{j+1}}+\frac{c_{j+1}^{2}}{B_{j}^{2} B_{j+1}^{2}}\left(\omega s+\frac{\gamma^{2}}{q}\right),
$$

and the price informativeness is given by

$$
I=\frac{1}{\operatorname{Var}\left(D \mid P_{j}\right)} .
$$

We demonstrate the robustness of the effects of options on information acquisition and the underlying asset in the dynamic model as follows.

Proposition 4.4. When $C \in\left(C_{2}, C_{1}\right)$, cutoffs $C_{3}$ and $C_{4}$ exists, which satisfies the following condition:

(1) When $C>C_{4}$, introducing an options market increases the population of informed investors, increases price informativeness, increases the expected asset price, and decreases price change volatility.

(2) When $C<C_{3}$, introducing an options market decreases the population of informed investors, decreases price informativeness, decreases the expected asset price, and increases price change volatility.

where $C_{3}$ and $C_{4}$ are defined as in the Appendix and $C_{3}<C_{4}$.

Findings regarding price reactions to earnings announcements in the U.S. market are also conflicting, as previous studies suggest that options listing decreased earnings announcements' surprise before 1980 (Jennings and Starks, 1986, Skinner, 1990, Damodaran and Lim, 1991 and Ho, 1993), but increases earnings announcements' surprise after 1980 (Mendenhall and Fehrs, 1999). The proxy for the price reactions to public information in trading round $j$ is $\frac{c_{j} z}{B_{j}}$, which decreases with $B_{j}$. When investors have more information about fundamental value, intuitively, the surprise to earnings announcements would be smaller. The result presented below shows that the effect of options listing on the price reactions to public information depends on the information acquisition cost. This result also differs from that by Cao (1999), who concludes that options listing decreases price reactions to public information. 
Proposition 4.5. When $C \in\left(C_{2}, C_{1}\right)$,

(1) When $C>C_{4}$, introducing an options market decreases price reactions to public information.

(2) When $C<C_{3}$, introducing an options market increases price reactions to public information.

where $C_{3}$ and $C_{4}$ are defined as in the Appendix and $C_{3}<C_{4}$.

As shown in Corollary 4.3, the precision of public information also affects investors' incentive to acquire information. Thus, we can expect the effect of an options market on information acquisition and asset prices to depend on the precision of public information. According to Proposition 4.6, the effects of options in the economy with precise public information are similar to those with high information acquisition costs, whereas the effects of options in an economy with imprecise public information are similar to those with low information acquisition costs. The population of informed investors is low when public information is precise before the introduction of options, which leads to a high demand for options and high option prices. Introducing an options market then provides informed investors with an opportunity to earn profits from selling options to cover the information acquisition cost, which increases investors' incentive to acquire information. When public information is imprecise, the population of informed investors is high, leading to low option prices. Thus, investors can use cheap options instead of information to reduce risk, which lowers investors' incentives to acquire information.

Proposition 4.6. When $F_{K} \in\left(F_{2}, F_{1}\right)$,

(1) When $F_{K}>F_{4}$, introducing an options market increases investors' incentive to acquire information, increases price informativeness, increases the expected asset price and decreases price change volatility.

(2) When $F_{K}<F_{3}$, introducing an options market decreases investors' incentive to acquire information, decreases price informativeness, decreases the expected asset price and increases price change volatility.

where $F_{3}$ and $F_{4}$ are defined as in the Appendix and $F_{3}<F_{4}$.

\subsection{Effect of additional trading rounds}

As argued by Brennan and Cao (1996), additional trading rounds have a similar effect to derivatives in improving investors' welfare. However, whether additional trading rounds have similar effects to an option market in affecting investors' incentive to acquire information is unclear. This issue is important because it has important implications on the after-hour or round-the-clock trading, which is associated high operational costs. This section formally addresses this question. 
We assume that introducing additional trading rounds increases trading time from $t$ to $s$, where $s>t$. The increase in trading time from $t$ to $s$ can be interpreted as after-hour or roundthe-clock trading. Additional trading time increases the number of time intervals and the last time interval is $[(L-1) z, L z)$, where $L$ is the largest integer satisfying $L z \leq s .{ }^{14}$ Before each trading round, a public signal is released. The public signal before trading round $j$ is

$$
S_{c, j}=D+\epsilon_{c, j}
$$

where $j=1,2 \ldots K, K+1, \ldots L$ and $\epsilon_{c, j}$ follows normal distribution $N\left(0, \frac{1}{c_{j} z}\right) . \epsilon_{c, j}$ is independent cross trading sessions and is independent of noise in investors' private signal. The analysis follows the dynamic model without options. The expected utilities of informed investors and uninformed investors in the economy with additional trading rounds are given by:

The expected utility of informed investors is:

$$
U_{I}=-\frac{1}{\sqrt{\operatorname{Var}\left(D-P_{1}\right) B_{i, 1}}} \exp \left[-\gamma W_{0}+\gamma C-\frac{\gamma \bar{X}^{2}}{2 B_{0}^{2} \operatorname{Var}\left(D-P_{0}\right)}\right] \times \prod_{j=2}^{j=L} \frac{1}{\sqrt{1+\frac{c_{j} z\left(B_{j}-B_{i, j}\right)^{2}}{B_{i, j-1} B_{j}^{2}}}},
$$

and the expected utility of uninformed investors is:

$$
U_{U}=-\frac{1}{\sqrt{\operatorname{Var}\left(D-P_{1}\right) B_{U, 1}}} \exp \left[-\gamma W_{0}-\frac{\gamma \bar{X}^{2}}{2 B_{0}^{2} \operatorname{Var}\left(D-P_{0}\right)}\right] \times \prod_{j=2}^{j=L} \frac{1}{\sqrt{1+\frac{c_{j} z\left(B_{j}-B_{U, j}\right)^{2}}{B_{U, j-1} B_{j}^{2}}}}
$$

where $B_{i, j}=h+s+\frac{\omega^{2} s^{2} q}{\gamma^{2}}+\sum_{k=1}^{j} c_{k} z, B_{U, j}=h+\frac{\omega^{2} s^{2} q}{\gamma^{2}}+\sum_{k=1}^{j} c_{k} z$ and $B_{j}$ is defined as above It is obvious that gain $\Delta_{G}$ from additional trading rounds is $\frac{B_{i, 1}}{B_{U, 1}} \prod_{j=K+1}^{j=L} \frac{1+\frac{c_{j} z\left(B_{j}-B_{i, j}\right)^{2}}{B_{i, j-1} B_{j}^{2}}}{1+\frac{c_{j} z\left(B_{j}-B_{U, j}\right)^{2}}{B_{U, j-1} B_{j}^{2}}}$. If $\Delta_{G}$ is larger than 1 , additional trading rounds provide a greater benefit to informed investors than uninformed ones. Then, investors have a greater incentive to acquire information after the introduction of additional trading rounds. If $\Delta_{G}$ is less than 1, additional trading rounds decrease investors' incentive to acquire information. Proposition 4.7 shows that additional trading opportunities encourage more investors to acquire information when the information cost is high, but discourage investors from acquiring information when this cost is low. Although additional trading opportunities improve the welfare of all investors (Brennan and Cao, 1996) owing to more risk-sharing opportunities, the benefits are asymmetric for different groups. When the population of informed investors is high because of low information acquisition costs, this additional benefit is

\footnotetext{
${ }^{14}$ This modeling about after-hour or round-the-clock trading is similar to Brennan and Cao (1996). The only difference is that we assume there are approximate continuous trading times, while they assume discrete trading sessions.
} 
low for informed investors because of the high competition within this group, whereas the benefit is high for uninformed investors. Thus, investors' incentive to acquire information is diminished and the equilibrium population of informed investors is reduced. When the cost is high, the opposite effect arises.

Proposition 4.7. When $C \in\left(C_{2}, C_{1}\right)$,

(1) When $C>C_{4}$, introducing additional trading rounds increases the population of informed investors, increases price informativeness, increases the expected asset price, decreases price change volatility and decrease price reactions to public information.

(2) When $C<C_{3}$, introducing additional trading rounds decreases the population of informed investors, decreases price informativeness, decreases expected asset price, increases price change volatility and increases price reactions to public information.

where $C_{3}$ and $C_{4}$ are defined in the Appendix and $C_{3}<C_{4}$.

\section{Discussion}

The previous sections focus on the analysis of an options market. Considering some general derivatives is also interesting. Thus, this section provides a further analysis of the derivatives that are modeled by Cao (1999) and shows that our main mechanism is robust to the use of derivatives other than options.

Following Cao (1999), we assume that a derivative asset's payoff is a function of $D$ and $P$. The specific function is denoted by $g(|D-P|)$, where $g(\cdot)$ is a monotonic function. We assume that informed investor $i$ 's demand for this derivative is $X_{G i}$, and uninformed investors' demand for this derivative is $X_{G U}$. Moreover, the equilibrium price of this derivative is denoted by $P_{G}$. Following Cao (1999), we obtain the following results regarding investors' demand and equilibrium prices:

$$
P=\bar{D}-\frac{\gamma \bar{X}}{B}+\frac{\left(\omega s+\frac{\omega^{2} s^{2} q}{\gamma^{2}}\right)\left(D-\bar{D}+\frac{\gamma}{\omega s} n\right)}{B},
$$

Informed investor $i$ 's demand is:

$$
X_{i}=\frac{E\left(D \mid \mathcal{F}_{i}\right)-P}{\gamma \operatorname{Var}\left(D \mid \mathcal{F}_{i}\right)}
$$

Uninformed investors' demand is:

$$
X_{U}=\frac{E\left(D \mid \mathcal{F}_{U}\right)-P}{\gamma \operatorname{Var}\left(D \mid \mathcal{F}_{U}\right)},
$$

Informed investors' demand for the derivative satisfies:

$$
\int_{0}^{+\infty}\left(g(y)-P_{G}\right) \exp \left[-B_{i} y^{2} / 2-\gamma X_{G i} g(y)\right] d y=0
$$


Uninformed investors' demand for the derivative satisfies:

$$
\int_{0}^{+\infty}\left(g(y)-P_{G}\right) \exp \left[-B_{U} y^{2} / 2-\gamma X_{G U} g(y)\right] d y=0
$$

The market clearing condition is:

$$
\omega X_{G i}+(1-\omega) X_{G U}=0
$$

Then, the expected utility of informed investors is:

$$
\begin{gathered}
U_{I}^{G}=U_{I} \sqrt{\frac{2 B_{i}}{\pi}} \int_{0}^{+\infty} \exp \left[-B_{I} y^{2} / 2-\gamma\left(X_{G i}-P_{G}\right) g(y)\right] d y, \\
U_{U}^{G}=U_{U} \sqrt{\frac{2 B_{U}}{\pi}} \int_{0}^{+\infty} \exp \left[-B_{U} y^{2} / 2-\gamma\left(X_{G U}-P_{G}\right) g(y)\right] d y,
\end{gathered}
$$

We know the gain from information with this derivative is $G=\left(U_{U}^{G} / U_{I}^{G}\right)^{2}$. Because obtaining analytical solutions is difficult, we rely on numerical studies. In the numerical studies, we consider two special cases for $g(\cdot)$ : first, $g(y)=y$; second, $g(y)=y^{2}$. In particular, we compare the gain from information in the economy with and without this derivative, given the population of informed investors. The results are illustrated in Figure 5 and Figure $6 .{ }^{15}$ The gain from information is clearly larger in the economy with derivatives than in that without derivatives when the population of informed investors is small. The opposite results is obtained when the population of informed investors is large.

It is noticed that introducing a call option at the money is equivalent to introducing a derivative with payoff $|D-P|$. Because the payoff of a call option at the money is given by $C=\max (D-$ $P, 0)=(|D-P|+V-P) / 2$, buying one call option at the money is equivalent to buying 0.5 share of a straddle given above and 0.5 share of the underlying asset. Thus, a call option at the money has same effects on information acquisition and the underlying asset market as the straddle with payoff $|D-P|$.

\section{Conclusions}

This paper examines the effect of introducing an options market on investors' incentive to acquire private information and the pricing behaviour of the underlying asset. As a novel finding, this paper demonstrates that introducing an options market increases investors' incentive to acquire

\footnotetext{
${ }^{15}$ The detailed proof can be found in Cao (1999). We set $\mathrm{h}=1, \mathrm{~s}=1, \mathrm{q}=1$ and $\gamma=0.5$ in the Figure 5 and Figure 6
} 


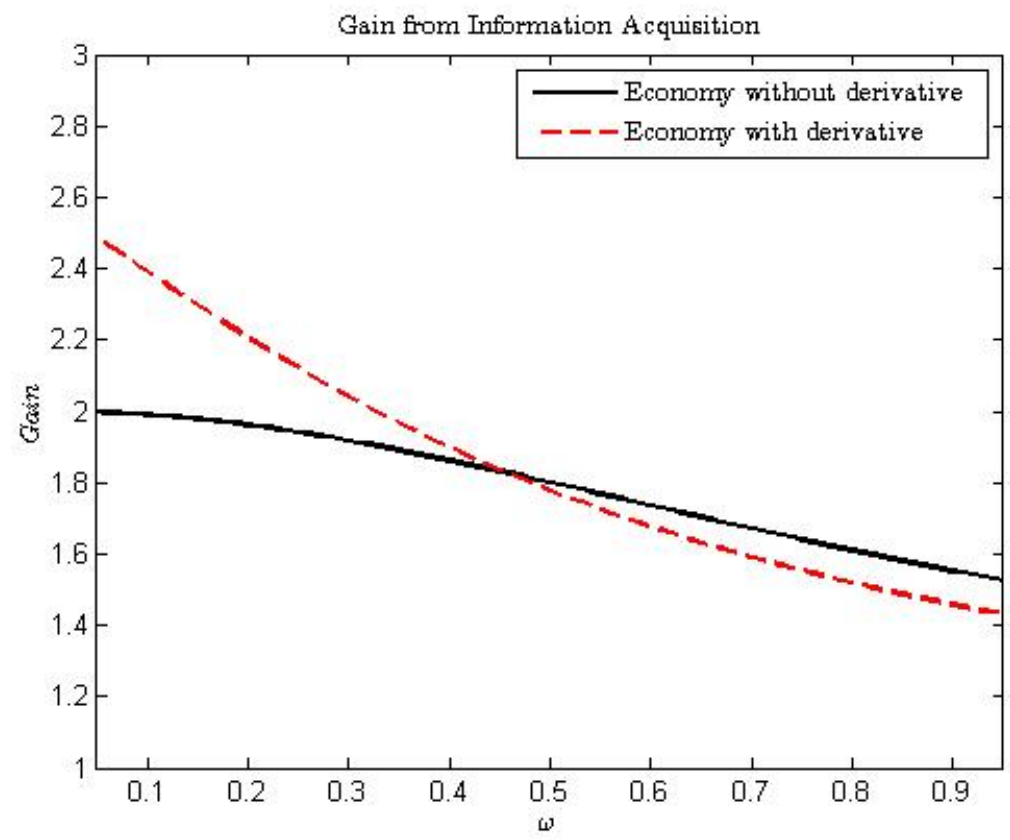

Figure 5: Gain from Information Acquisition: $g(y)=y$

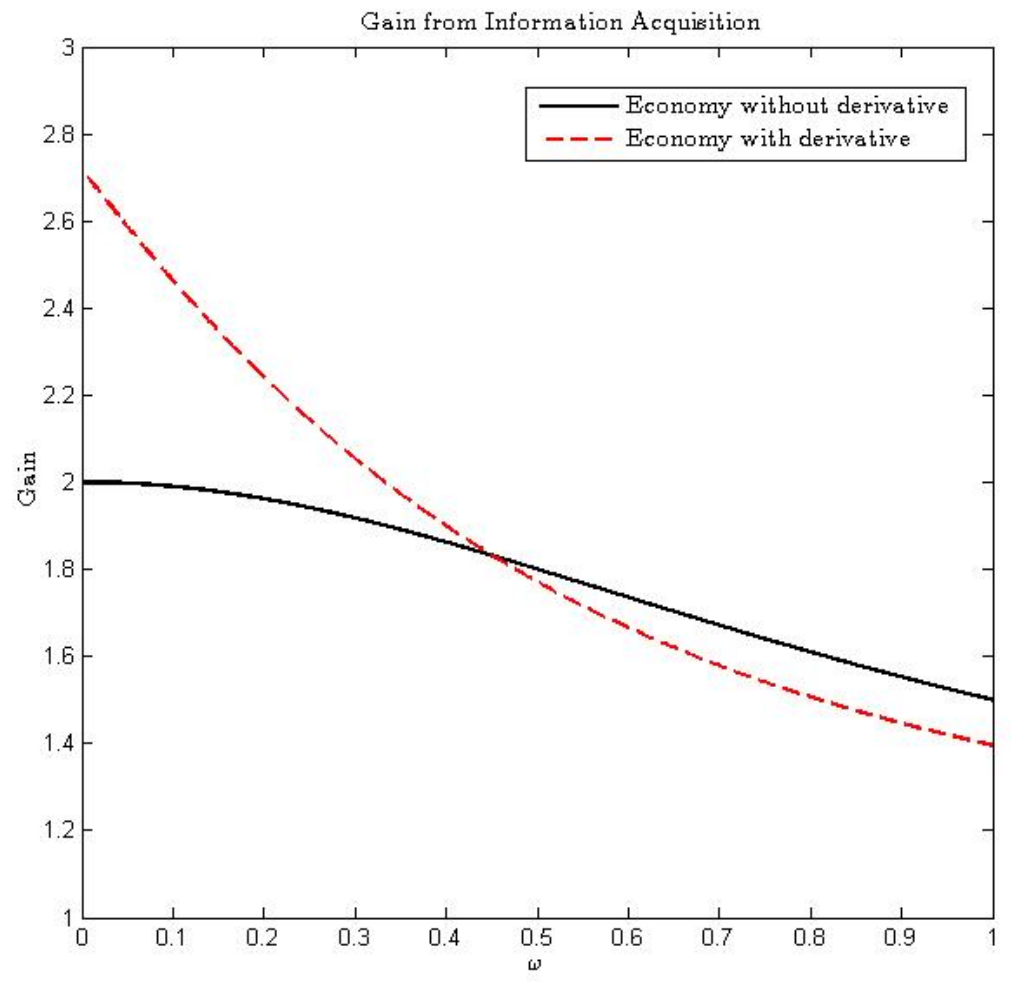

Figure 6: Gain from Information Acquisition: $g(y)=y^{2}$ 
private information when the information acquisition cost is high, but decreases their incentive to acquire private information when the cost is low. Consequently, when the information acquisition cost is high, an options market increases the underlying asset's price informativeness, increases the expected asset price, decreases price volatility and decreases market responses to earnings announcements. By contrast, when the information acquisition cost is low, the opposite effects arise. These results can provide a potentially unified theory for the conflicting findings on the effect of options listing in the U.S. market and international markets.

Moreover, this paper also provides some innovative predictions: First, although we do not formally study the effect of options listing on market liquidity, this paper predicts that an options market increases the liquidity of the underlying asset market in an illiquid market and decreases liquidity in a liquid market. When the population of informed investors is high, price is less sensitive to noisy supply, reducing the price impact of the noisy supply. Thus, the market has high liquidity. As shown above, a large population of informed investors leads to a higher supply for options than demand, which is associated with low option prices and low profits from selling options. Introducing an options market decreases investors' incentive to acquire information, which results in lower price informativeness. Consequently, the price impact of the noisy supply increases and market liquidity deteriorates. Opposite effect of options listing arises in illiquid market with a small population of informed investors. This is consistent with the findings by Fedenia and Grammatikos (1992). Second, options listing has stabilizing effect (increasing price informativeness, raising asset price, decreasing price volatility and market reactions to earnings announcements) when the public information is precise, but has destabilization effect (decreasing price informativeness, decreasing asset price, increasing price volatility and market responses to earnings announcements) when the public information is imprecise. third, introducing an options market and implementing after-hour or round-the-clock trading have stabilizing effects (improving informational efficiency, decreasing price volatility) on the underlying assets with high information acquisition costs, such as small firms and firms with low analyst coverage; Fourth, introducing an options market and implementing after-hour or round-the-clock trading have destabilization effects (harming informational efficiency, increasing price volatility) on the underlying assets with low information acquisition costs, such as large or well-known firms and firms with high analyst coverage.

Although previous theoretical studies on derivatives find that introducing derivatives increase asset prices and decrease price volatilities (Cao, 1999 and Massa, 2002), these studies can not reconcile the findings: options listing increases asset prices, decreases price volatility and decreases price reactions to earning announcements in U.S. market before 1980, but yields the opposite effects after 1980. Further, these studies can not explain the findings: options listing tends to have stabilizing effects in emerging markets, such as India, but have destabilization effects in some 
developed markets, such as Germany. Our results not only explain these conflicting facts regarding the effects of options listing, but also shed new light on debates about whether a derivative market has (de)stabilizing effects on the underlying asset market.

Because we aim to obtain tractable solutions, our model assumes that there are no additional noisy traders after the initial trading round in the dynamic model. However, extending our model to consider time-varying noisy traders may provide an interesting future research avenue. Such as extension would also be useful for studying market liquidity in a general dynamic model. In addition, future research may study the effect of other financial innovations on investors' incentive to acquire information, as in the study by Simsek (2013a,b). More important, we notice that the options have no direct impact on underlying assets because of the assumptions of CARA utility and normal distributions. Although this feature helps to elucidate the effects of options on information acquisition, relaxing these assumptions and analyzing the effects derivatives on asset prices under general utility functions may provide a fruitful research avenue. We leave all of these to further studies. 


\section{References}

Admati, Anat R, 1985, A Noisy Rational Expectations Equilibrium for Multi-Asset Securities Markets, Econometrica, 53, 629-657.

Admati, Anat R and Paul Pfleiderer, 1988, Selling and Trading on Information In Financial Markets, American Economic Review, 78, 96-103.

Allen, Franklin and Douglas Gale, 1994, Financial Innovation and Risk Sharing, MIT Press, Cambridge, Mass.

Akerlof, George A, 1970, The Market for "Lemons": Quality Uncertainty and the Market Mechanism, The Quarterly Journal of Economics, 84, 488-500.

Back, Kerry, 1993, Asymmetric Information and Options, Review of Financial Studies, 3:1-24.

Bansal, Vipul K, Stephen W. Pruitt and K.C. John Wei, 1989, An Empirical Reexaminaiton of the Impact of CBOE Option Initiaiton on the Volatility and Trading Volume of the Underlying Equities: 1973-1986, Financial Review, 24, 19-29.

Bhattacharya, Utpal, Philip J. Reny and Matthew Spiegel, 1995, Destructive Interference in An Imperfectly Competitive Multi-Security Market, Journal of Economic Theory, 65, 136-170.

Bollen, Nicolas P.B, 1998, A Note on the Impact of Options on Stock Return Volatility, Journal of Banking and Finance, 22, 1181-1191.

Branch, Ben and Joseph E. Finnerty, 1981, The Impact of Option Listing On the Price and Volume of the Underlying Stock, Financial Review, 16, 1-15.

Breeden, Douglas, 1984, Futures Markets and Commodity Options: Hedging and Optimality in Incomplete Markets, Journal of Economic Theory, 32, 275-300.

Brennan, Michael and H.Henry CaO, 1996, Information, Trade, and Option Securities, Review of Financial Studies, 9, 163-208.

Brock, William, and Cars Hommes and Florian Wagener, 2009, More Hedging Instruments May Destabilize Markets, Journal of Economic Dynamics and Control, 33, 1912-1928.

Biais, Bruno and Pierre Hillion, 1994, Insider and Liquidity Trading in Stock and Options Markets, Review of Financial Studies, 7, 4, 743-780.

CaO, H.Henry, 1999, The Effect of Option Stocks on Information Acquisition and Price Behavior in a Rational Expectations Equilibrium, Review of Financial Studies, 12, 131-163.

CaO, H.Henry and Hui Ou-Yang, 2009, Differences of Opinion of Public Information and Speculative Trading in Stocks and Options, Review of Financial Studies, 22(1), 299-335.

Chabakauri, Georgy, Kathy Yuan and Konstantinos Zachariadis, 2014, Multi-Asset Noisy Rational Expectations Equilibrium with Contingent Claims, Working paper 
Conrad, Jennifer, 1989, The Price Effect of Option Introduction, Journal of Finance, 44, 487-498.

Damodaran, Aswath, and Joseph Lim,1991, The Effects Of Option Listing On The Underlying Stocks' Return Processes, Journal of Banking and Finance, 3, 15, 647-664.

Detemple, Jerome and Philippe Jorion, 1990, Option Listing and Stock Returns: An Empirical Analysis, Journal of Banking and Finance, 14, 781-801.

Detemple, Jerome and Larry Selden, 1991, A General Equilibrium Analysis of Option and Stock Market Interactions, International Economic Review, 32, 279-302.

Dieckmann, Stephan,2011, Rare Events Risk and Heterogeneous Beliefs: The Case of Incomplete Markets, Journal of Financial and Quantitative Analysis, 46, 459-488.

Dow, JAmes,1998, Arbitrage, Hedging, and Financial Innovation, Review of Financial Studies, 11, 739-755.

Duffie, Darrell and Rohit RAhi, 1995, Financial Market Innovation and Security Design: an Introduction, Journal of Economic Theory, 65, 1-42.

Easley, David, Maureen O'Hara and Liyan Yang, 2013, Differential Access to Price Information in Financial Markets, Journal of Financial and Quantitative Analysis, forthcoming.

Edwards, Franklin R., 1998a, Futures Trading and cash Market Volatility: Stock Index and Interest Rate Futures, Journal of Future Markets, 44, 63-68.

Edwards, Franklin R., 1998b, Does Futures Trading Increase Stock Market Volatility?, Financial Analyst Journal, 8, 421-439.

Fedenia, Mark and Theoharry Grammatikos, 1992, Options Trading and the Bid-Ask Spread on the Underlying Stocks, Journal of Business, 65, 335-351.

Freund, Steven, P. Douglas McCann and Gwendolyn P. Webb, 1994, A Regression Analysis of the Effects of Option Introduction on Stock Variances, Journal of Derivatives, 1, 25-38.

Galloway, Tina M. and James M. Miller, 1997, Index Futures Trading and Stock Return Volatility: Evidence From the Introduction of Mid Cap 400 Index Futures, Financial Review, 32, 845-866.

Grossman, Sanford, 1976, On The Efficiency Of Competitive Stock Markets When Traders Have Diverse Information, Journal of Finance, 31, 573-585.

Grossman, Sanford, 1988, An Analysis of the Implication for Stock and Futures Price Volatility of Program Trading and Dynamic Hedging Strategies, Journal of Business, 61, 275-298.

Grossman, Sanford, and Merton Miller, 1988, Liquidity And Market Structure, Journal of Finance, 43, 617-637.

Grossman, Sanford, and Joseph Stiglitz, 1980, On The Impossibility Of Informationally Efficient Markets, American Economic Review, 70, 393-408. 
Grundy, Bruce, and Maureen McNichols, 1989, Trade And The Revelation Of Information Through Prices And Direct Disclosure, Review of Financial Studies, 2, 495-526.

Guesnerie, Roger,and Jean-Charles Rochet 1993, (De)Stabilizing Speculation on Futures Markets: An Alternative View Point, European Economic Review, 37, 1043-1063.

Hamill, Philip A, Kwaku K. Opong,and Pat McGregor, 2002, Equity Option Listing in the UK: A Comparison Of market-Based Research Methodologies, Journal of Empirical Finance, 9, 1, 91-108.

Hayes, Samuel L, and Michale E. Tennenhaum, 1979, The Impact of Listed Options on the Underlying Shares, Financial Management, 8, 72-76.

He, Hua, and Jiang Wang, 1995, Differential Information And Dynamic Behavior Of Stock Trading Volume, Review of Financial Studies, 8, 919-972.

Heer, Burkhard, Mark Trede and Mark Wahrenburg, 1997, The Effect of Option Trading at the DTB on the Underlying Stocks' Return Variance, Empirical Economics, 22, 233-245.

Hellwig, Martin, 1980, On The Aggregation Of Information In Competitive Markets, Journal of Economic Theory, 22, 477-498.

Ho, Li-Chin Jennifer, 1993, Option Trading and the Relation Between Price and Earnings: A CrossSectional Analysis, Accounting Review, 68, 368-384.

Huang, Jennifer and Jiang Wang, 1997, Market Structure, Security Prices and Information Efficiency, Macroeconomic Dynamics, 1, 169-205.

Jennings, Robert and Laura Starks, 1986, Earnings Announcements, Stock Price Adjustment, and the Existence of Option Markets, Journal of Finance, 41, 107-125.

Jubinski, Daniel and Marc TomlJanovich, 2007, Options Listings And Individual Equity Volatility, Journal of Futures Markets, 27, 1, 1-27.

Kabir, Rezual, 2000, The Price and Volatility Effects of Stock Option Introduction: A Reexamination, Research in Banking and Finance, 1, 261-279.

Klemkosky, Robert C. and Terry S. Maness, 1980, The Impact of Options on the Underlying Securities, Journal of Portfolio Management, 9, 12-18.

Kim, Oliver and Robert E. Verrecchia, 1991, Trading Volume and Price Reactions to Public Announcements, Journal of Accounting Research, 29, 302-321.

Kyle, Albert S., 1985, Continuous Auctions and Insider Trading, Econometrica, 53, 6, 1315-1335.

Kumar, Raman, Atulya Sarin and Kuldeep Shastri, 1998, The Impact of Options Trading on the Market Quality of the Underlying Security: An Empirical Analysis, Journal of Finance, 53, 2, 717-732.

Massa, Massimo, 2002, Financial Innovation and Information: The Role Of Derivatives When A Market For Information Exists, Review of Financial Studies, 15, 927-957. 
Mayhew, Stewart and Vassil Mihov, 2000, Another Look at Option Listing Effects, working paper.

Mendenhall, Richard R. and Donald H. Fehrs, 1999, Option Listing and the Stock-Price Response to Earnings Announcements, Journal of Accounting and Economics, 27, 57-87.

NaIR, S.ABhilash, 2008, Impact Of Derivative Trading on Volatility of the Underlying: Evidence from Indian Stock Market, working paper, Conference On Money And Finance 2008, Mumbai

Rao, Ramesh P. and Christopher K. MA, 1987, The Effect of Call-Option-Listing Announcement on Shareholder Wealth, Journal of Business Research, 15, 449-465.

Ross, Stephen A., 1976, Options and Efficiency, Quarterly Journal of Economics, 90, 75-89.

Simsek, Alp, 2013a, Speculation and Risk Sharing with New Financial Assets, Quarterly Journal of Economics, 128-3, 1365-1396.

Simsek, Alp, 2013b, Financial Innovation and Portfolio Risks, American Economic Review Papers and Proceedings, 103-3, 398-401.

Skinner, Douglas, 1989, Options Market ans Stock Return Volatility, Journal of Financial Economics, $23,61-78$.

Skinner, Douglas, 1990, Options Markets and the Information Content of Accounting Earnings Release, Journal of Accounting And Economics, 13, 191-211.

Sorescu, Sorin M., 2000, The Effect of Options on Stock Prices: 1973-1995, The Journal of Finance, $55,1,487-514$.

Subrahmanyam, Avanidhar, 1992, Risk Aversion, Market Liquidity, and Price Efficiency, The Review of Financial Studies, 4, 3, 417-441.

Swan, EDward J., 2000, Building the Global Market, a 4000 Year History of Derivatives, Kluwer Law International, Boston.

Stephan, Jens A., and Robert E. Whaley, 1990, Intraday Price Change and Trading Volume Relations in the Stock and Stock Option Markets, The Journal of Finance, 45, 191-220.

Stoll, Hans, 1978a, The Pricing of Security Dealer Services: An Empirical Study Of NASDAQ Stocks, The Journal of Finance, 33, 1153-1172.

Stoll, Hans, 1978b, The Supply Of Dealer Services In Securities Markets, The Journal of Finance, 33 , $1133-1151$

Wang, JiAng, 1993, A Model Of Intertemporal Asset Prices Under Asymmetric Information, Review of Economics Studies, 60, 249-282.

Wang, JiAng, 1994, A Model Of Competitive Stock Trading Volume, Journal of Political Economy, 102, 127-168.

Weyl, Glen, 2007, Is Arbitrage Socially Beneficial,2007 Princeton University working paper. 


\section{Appendix}

This appendix provides all proofs omitted above.

\section{Proof of Proposition 2.1.}

$$
\begin{gathered}
E V_{i}=-\exp \left[-\gamma W_{0}-\frac{\bar{X}^{2}}{2 \gamma B^{2} \operatorname{Var}(D-P)}\right] \times \frac{1}{\sqrt{\operatorname{Var}(D-P) B_{i}}} \\
E V_{U}=-\exp \left[-\gamma W_{0}-\frac{\bar{X}^{2}}{2 \gamma B^{2} \operatorname{Var}(D-P)}\right] \times \frac{1}{\sqrt{\operatorname{Var}(D-P) B_{U}}}
\end{gathered}
$$

The Gain $G$ in the case without derivative security is $\frac{B_{i}}{B_{U}}$. In the equilibrium, investors should break even the gain from information acquisition and cost. If $G(0) \leq \exp (2 \gamma C)$, the equilibrium fraction of informed investors $\omega^{*}=0$. If $G(0)>\exp (2 \gamma C)>G(1)$, the equilibrium fraction of informed investors $\omega^{*} \in(0,1)$ which satisfies $G\left(\omega^{*}\right)=\exp (2 \gamma C)$. If $\exp (2 \gamma C) \leq G(1)$, the equilibrium fraction of informed investors $\omega^{*}=1$.. Therefore, we can get the lemma. And $C_{d 1}$ satisfy $G(0)=\exp \left(2 \gamma C_{d 1}\right)$ and $C_{d 2}$ satisfy $G(1)=\exp \left(2 \gamma C_{d 2}\right)$. Since $G$ is a decreasing function of $\omega$, it is obvious that $\omega^{*}$ is a decreasing function with $C$ when $C_{d 2}<C<C_{d 1}$

Proof of Proposition 3.1 and Proof of Lemma 3.1. To prove that price function and demands are in the equilibrium, we should prove that the market is clearing in the equilibrium and Euler condition holds for the demand of different assets. Given the informed investors and uninformed investors' demand of the risky assset and options, we have the following market clearing condition:

for the stock, we have

$$
\omega X_{i}+(1-\omega) X_{U}+n=\bar{X}
$$

It is clear that the price in the proposition clears the market of the risky asset.

for the options, we have

$$
\frac{\omega}{\gamma}\left(B-B_{i}\right)+(1-\omega)\left(B-B_{U}\right)=0
$$

Since $B=h+\omega s+\frac{\omega^{2} s^{2} q}{\gamma^{2}}+c$, it is clear that the option market is clearing. 
Next we will show the Euler condition holds for the demand of different assets. For informed investor $i$ 's final wealth is given by:

$$
W_{i, 1}=W_{i, 0}+X_{i}(D-P)+\int_{0}^{\infty} X_{i, C G}\left[(D-G)^{+}-P_{C G}\right] d G+\int_{-\infty}^{0} X_{i, P G}\left[(G-D)^{+}-P_{P G}\right] d G
$$

Given the equilibrium $X_{i, C G}$ and $X_{i, P G}$, we firstly prove that the proposed demand of risky asset satisfies the first order condition for investors' optimization problem.

Due to $D^{2}=2 \int_{0}^{\infty}(D-G)^{+} d G+2 \int_{-\infty}^{0}(G-D)^{+} d G$, we have

$$
\left.W_{i, 1}=W_{i, 0}+X_{i}(D-P)+\frac{B-B_{i}}{\gamma} \frac{D^{2}}{2}-\frac{B-B_{i}}{\gamma}\left(\int_{0}^{\infty} P_{C G} d G+\int_{-\infty}^{0} P_{P G}\right] d G\right)
$$

Informed investors maximize expected utility

$$
\begin{gathered}
-E\left\{\exp \left(-\gamma W_{i, 1}\right) \mid \mathcal{F}_{i}\right\} \\
\left.=-E\left\{\exp \left[-\gamma\left(W_{i, 0}+X_{i}(D-P)+\frac{B-B_{i}}{\gamma} \frac{D^{2}}{2}-\frac{B-B_{i}}{\gamma}\left(\int_{0}^{\infty} P_{C G} d G+\int_{-\infty}^{0} P_{P G}\right] d G\right)\right)\right] \mid \mathcal{F}_{i}\right\} \\
\left.\left.=-\frac{1}{\sqrt{1+\left(B-B_{i}\right) \frac{1}{B_{i}}}} \exp \left[-\gamma W_{i, 0}+\left(B-B_{i}\right)\left(\int_{0}^{\infty} P_{C G} d G+\int_{-\infty}^{0} P_{P G}\right] d G\right)\right)\right]+\gamma X_{i} P-\gamma X_{i} E\left(D \mid \mathcal{F}_{i}\right) \\
\left.-\frac{B-B_{i}}{2} E^{2}\left(D \mid \mathcal{F}_{i}\right)+\frac{1}{2}\left(\gamma X_{i}+\left(B-B_{i}\right) E\left(D \mid \mathcal{F}_{i}\right)\right)^{2} \frac{1}{B_{i}} \frac{1}{1+\left(B-B_{i}\right) \frac{1}{B_{i}}}\right]
\end{gathered}
$$

FOC, we have: $\gamma P-\gamma E\left(D \mid \mathcal{F}_{i}\right)+\left(\gamma X_{i}+\left(B-B_{i}\right) E\left(D \mid \mathcal{F}_{i}\right)\right) \frac{\gamma}{B}=0 \Rightarrow X_{i}=\frac{B_{i}}{\gamma}\left(E\left(D \mid \mathcal{F}_{i}\right)-P\right)-$ $\frac{1}{\gamma}\left(B-B_{i}\right) P$

This proves that the proposed demand of risky asset satisfies the first order condition for investors' optimization problem. Now we show that proposed demands and prices for the options satisfy the Euler conditions. This means that we need to prove that:

$$
E\left[\left((D-G)^{+}-P_{C G}\right) \exp \left(-\gamma W_{i, 1}\right) \mid \mathcal{F}_{i}\right]=0 \quad E\left[\left((G-D)^{+}-P_{P G}\right) \exp \left(-\gamma W_{i, 1}\right) \mid \mathcal{F}_{i}\right]=0
$$

Since $\int_{0}^{+\infty}(P-G) N(\sqrt{B}(P-G)) d G+\int_{0}^{+\infty} \frac{1}{\sqrt{B}} \exp \left(-\frac{B(P-G)^{2}}{2}\right) d G+\int_{\infty}^{0}(G-P) N(\sqrt{B}(G-P)) d G+$ $\int_{0}^{+\infty} \frac{1}{\sqrt{B}} \exp \left(-\frac{B(G-P)^{2}}{2}\right) d G$

$$
\begin{aligned}
& =\int_{0}^{+\infty}(P-G) N(\sqrt{B}(P-G)) d G+\int_{\infty}^{0}(G-P) N(\sqrt{B}(G-P)) d G+\frac{1}{B} \\
& =\int_{0}^{+\infty}(P-G) \int_{-\infty}^{\sqrt{B}(P-G)} \frac{1}{\sqrt{2 \pi}} \exp \left(-\frac{1}{2} x^{2}\right) d x d G \\
& +\int_{-\infty}^{0}(G-P) \int_{-\infty}^{\sqrt{B}(G-P)} \frac{1}{\sqrt{2 \pi}} \exp \left(-\frac{1}{2} x^{2}\right) d x d G+\frac{1}{B} \\
& =\int_{-\infty}^{P \sqrt{B}} \frac{1}{\sqrt{2 \pi}} \int_{0}^{P-\frac{x}{\sqrt{B}}}(P-G) d G \exp \left(-\frac{1}{2} x^{2}\right) d x+\int_{-\infty}^{-P \sqrt{B}} \frac{1}{\sqrt{2 \pi}} \int_{P+\frac{x}{\sqrt{B}}}^{0}(G-P) d G \exp \left(-\frac{1}{2} x^{2}\right) d x+\frac{1}{B} \\
& =\int_{-\infty}^{P \sqrt{B}} \frac{1}{\sqrt{2 \pi}}\left(\frac{P^{2}}{2}-\frac{1}{2 B} x^{2}\right) \exp \left(-\frac{1}{2} x^{2}\right) d x+\int_{-\infty}^{-P \sqrt{B}} \frac{1}{\sqrt{2 \pi}}\left(\frac{P^{2}}{2}-\frac{1}{2 B} x^{2}\right) \exp \left(-\frac{1}{2} x^{2}\right) d x+\frac{1}{B}
\end{aligned}
$$




$$
\begin{aligned}
& =\frac{P^{2}}{2} N(P \sqrt{B})+\frac{P^{2}}{2} N(-P \sqrt{B})-\frac{1}{2 B} \int_{-\infty}^{P \sqrt{B}} \frac{1}{\sqrt{2 \pi}} x^{2} \exp \left(-\frac{1}{2} x^{2}\right) d x \\
& -\frac{1}{2 B} \int_{-\infty}^{-P \sqrt{B}} \frac{1}{\sqrt{2 \pi}} x^{2} \exp \left(-\frac{1}{2} x^{2}\right) d x+\frac{1}{B} \\
& =\frac{P^{2}}{2}+\frac{1}{2 B}
\end{aligned}
$$

This indicates that $\left.\int_{0}^{\infty} P_{C G} d G+\int_{-\infty}^{0} P_{P G}\right] d G=\frac{1}{2}\left(\frac{1}{B}+P^{2}\right)$. Then we put $\int_{0}^{\infty} P_{C G} d G+$ $\left.\int_{-\infty}^{0} P_{P G}\right] d G=\frac{1}{2}\left(\frac{1}{B}+P^{2}\right)$ into final wealth, we have:

$$
\begin{gathered}
W_{i, 1}=W_{i, 0}+\left[\frac{B_{i}}{\gamma}\left(E\left(D \mid \mathcal{F}_{i}\right)-P\right)-\frac{1}{\gamma}\left(B-B_{i}\right) P\right](D-P)+\frac{B-B_{i}}{\gamma} \frac{D^{2}}{2}-\frac{B-B_{i}}{\gamma} \frac{1}{2}\left(\frac{1}{B}+P^{2}\right) \\
=W_{i, 0}+\frac{B_{i}}{\gamma}\left(E\left(D \mid \mathcal{F}_{i}\right)-P\right)(D-P)+\frac{B-B_{i}}{\gamma} \frac{D^{2}}{2}-\frac{B-B_{i}}{\gamma} \frac{1}{2}\left(\frac{1}{B}+P^{2}\right) \\
=W_{i, 0}+\frac{B_{i}}{\gamma}\left(E\left(D \mid \mathcal{F}_{i}\right)-P\right)(D-P)+\frac{B-B_{i}}{2 \gamma}\left[(D-P)^{2}-\frac{1}{B}\right]
\end{gathered}
$$

For the Euler Equation $E\left[\left((D-G)^{+}-P_{C G}\right) \exp \left(-\gamma W_{i, 1}\right) \mid \mathcal{F}_{i}\right]=0$, we have $E\left[\exp \left(-\gamma W_{i, 1}\right) \mid \mathcal{F}_{i}\right]=-\frac{1}{\sqrt{\frac{B}{B_{i}}}} \exp \left[-\gamma W_{i, 0}+\frac{B-B_{i}}{2 B}-\frac{B_{i}}{2}\left(E\left(D \mid \mathcal{F}_{i}\right)-P\right)^{2}\right] . \quad$ Let $x=D-P$, $\mu=E\left(D \mid \mathcal{F}_{i}\right)-P, B_{i}=\operatorname{Var}\left(D-P \mid \mathcal{F}_{i}\right)$

$E\left[(D-G)^{+} \exp \left(-\gamma W_{i, 1}\right) \mid \mathcal{F}_{i}\right]=\int_{G-P}^{+\infty}[x-(G-P)] \exp \left[-\gamma W_{i, 0}+\frac{B-B_{i}}{2 B}\right] \frac{\sqrt{B_{i}}}{\sqrt{2 \pi}} \exp \left(-B_{i} \mu x-\frac{B-B_{i}}{2} x^{2}-\right.$ $\left.\frac{B_{i}(x-\mu)^{2}}{2}\right) d x$

$=\int_{G-P}^{+\infty}[x-(G-P)] \exp \left[-\gamma W_{i, 0}+\frac{B-B_{i}}{2 B}-\frac{B_{i}}{2}\left(E\left(D \mid \mathcal{F}_{i}\right)-P\right)^{2}\right] \frac{\sqrt{B_{i}}}{\sqrt{2 \pi}} \exp \left(-\frac{B}{2} x^{2}\right) d x$

$=\exp \left[-\gamma W_{i, 0}+\frac{B-B_{i}}{2 B}-\frac{B_{i}}{2}\left(E\left(D \mid \mathcal{F}_{i}\right)-P\right)^{2}\right]\left[\int_{G-P}^{+\infty} x \frac{\sqrt{B_{i}}}{\sqrt{2 \pi}} \exp \left(-\frac{B}{2} x^{2}\right) d x+\int_{G-P}^{+\infty}(P-\right.$

G) $\left.\frac{\sqrt{B_{i}}}{\sqrt{2 \pi}} \exp \left(-\frac{B}{2} x^{2}\right) d x\right]$

$=\exp \left[-\gamma W_{i, 0}+\frac{B-B_{i}}{2 B}-\frac{B_{i}}{2}\left(E\left(D \mid \mathcal{F}_{i}\right)-P\right)^{2}\right]\left[(P-G) \frac{1}{\sqrt{\frac{B}{B_{i}}}} N(\sqrt{B}(P-G))+\frac{\sqrt{B_{i}}}{B} \exp \left(-\frac{B(P-G)^{2}}{2}\right)\right]$

(where $\int_{G-P}^{+\infty}(P-G) \frac{\sqrt{B_{i}}}{\sqrt{2 \pi}} \exp \left(-\frac{B}{2} x^{2}\right) d x=\int_{\sqrt{B}(G-P)}^{+\infty}(P-G) \frac{\sqrt{B_{i}}}{\sqrt{2 \pi} \sqrt{B}} \exp \left(-\frac{y^{2}}{2}\right) d y=(P-G) \frac{1}{\sqrt{\frac{B}{B_{i}}}}[1-$ $N(\sqrt{B}(G-P))]=(P-G) \frac{1}{\sqrt{\frac{B}{B_{i}}}} N(\sqrt{B}(P-G))$

$\left.\int_{G-P}^{+\infty} x \frac{\sqrt{B_{i}}}{\sqrt{2 \pi}} \exp \left(-\frac{B}{2} x^{2}\right) d x=\int_{\sqrt{B}(G-P)}^{+\infty} y \frac{\sqrt{B_{i}}}{\sqrt{2 \pi} B} \exp \left(-\frac{y^{2}}{2}\right) d y=\frac{\sqrt{B_{i}}}{B} \exp \left(-\frac{B(G-P)^{2}}{2}\right)\right)$

From the Euler Condition, we have $P_{C G}=(P-G) N(\sqrt{B}(P-G))+\frac{1}{\sqrt{B}} \exp \left(-\frac{B(P-G)^{2}}{2}\right)$. This verifies the proposed the price function in the proposition. Following the similar procedure, it is obvious that the price function of put option takes the form in the propositions. Following the similar procedure, we can prove that uninformed investors' demand functions of risky asset and options take the forms in the proposition.

Proof of Lemma 3.2. In the case with derivative security, for the informed investors' utility, 
we put $X_{i}=\frac{E\left(D \mid \mathcal{F}_{i}\right)-P}{\operatorname{Var}\left(D \mid \mathcal{F}_{i}\right)}$ and $X_{i, G}=\frac{1}{2 \gamma}\left(\frac{1}{P_{G}}-\frac{1}{\operatorname{Var}\left(D \mid \mathcal{F}_{i}\right)}\right)$ into

$$
\begin{gathered}
-\frac{1}{\sqrt{1+2 \gamma X_{i, G} \operatorname{Var}\left(D \mid \mathcal{F}_{i}\right)}} \exp \left[-\gamma\left(W_{i, 0}-X_{i, G} P_{G}\right)\right. \\
\left.+\frac{\operatorname{Var}\left(D \mid \mathcal{F}_{i}\right)\left[\gamma X_{d}-\frac{E\left(D \mid \mathcal{F}_{i}\right)-P}{\operatorname{Var}\left(D \mathcal{F}_{i}\right)}\right]^{2}}{2\left(1+2 \gamma X_{d, G} \operatorname{Var}\left(D \mid \mathcal{F}_{i}\right)\right)}-\frac{1}{2} \frac{\left(E\left(D \mid \mathcal{F}_{i}\right)-P\right)^{2}}{\operatorname{Var}\left(D \mid \mathcal{F}_{i}\right)}\right]
\end{gathered}
$$

$\Leftrightarrow$

$$
-\frac{1}{\sqrt{\frac{\operatorname{Var}(D-P)}{P_{G}}}} \exp \left[-\gamma\left(W_{i, 0}+\frac{(1-\omega) s}{2 B}-\frac{\bar{X}^{2}}{2 \gamma B^{2} \operatorname{Var}(D-P)}\right)\right.
$$

we follow the same calculation, we can get the uninformed investors' utility as

$$
-\frac{1}{\sqrt{\frac{\operatorname{Var}(D-P)}{P_{G}}}} \exp \left[-\gamma\left(W_{i, 0}-\frac{\omega s}{2 B}\right)--\frac{\bar{X}^{2}}{2 \gamma B^{2} \operatorname{Var}(D-P)}\right]
$$

Therefore, the gain $G$ in the case with derivative security is $\exp \left(\frac{s}{B}\right)$

Proof of Proposition 3.2. Whether the introduction of derivative security increase the fraction of informed investors depends on $\exp \left(\frac{s}{B}\right)-\frac{B_{i}}{B_{U}}$. We can transform $\exp \left(\frac{s}{B}\right)-\frac{B_{i}}{B_{U}}$ into $\frac{s}{B}-$ $\ln \left(\frac{B_{i}}{B_{U}}\right)$. From the proof of Proposition 4.2, we know that $\sum_{j=2}^{T}\left(\frac{1}{B_{j-1}}-\frac{1}{B_{j}}\right) \frac{\left(B_{j}-B_{i, j}\right)^{2} / B_{j-1}}{1+\left(B_{i, j-1}-B_{j-1}\right) / B_{j-1}}$ $=\int_{\frac{1}{B_{T}}}^{\frac{1}{B_{1}}} \frac{(1-\omega)^{2} s^{2} t}{1+(1-\omega) s t} d t=(1-\omega) s\left(\frac{1}{B_{1}}-\frac{1}{B_{T}}\right)-\left[\ln \left(1+\frac{(1-\omega) s}{B_{1}}\right)-\ln \left(1+\frac{(1-\omega) s}{B_{T}}\right)\right]$

when $B_{T} \rightarrow \infty$, we have $\sum_{j=2}^{\infty}\left(\frac{1}{B_{j-1}}-\frac{1}{B_{j}}\right) \frac{\left(B_{j}-B_{i, j}\right)^{2} / B_{j-1}}{1+\left(B_{i, j-1}-B_{j-1}\right) / B_{j-1}}=\frac{(1-\omega) s}{B_{1}}-\ln \left(1+\frac{(1-\omega) s}{B_{1}}\right)$

Furthermore, $\sum_{j=2}^{\infty}\left(\frac{1}{B_{j-1}}-\frac{1}{B_{j}}\right) \frac{\left(B_{j}-B_{U, j}\right)^{2} / B_{j-1}}{1+\left(B_{i, j-1}-B_{j-1}\right) / B_{j-1}}=\frac{-\omega s}{B_{1}}-\ln \left(1+\frac{-\omega s}{B_{1}}\right)$

It is obvious that

$$
\begin{gathered}
\frac{s}{B_{1}}-\ln \left(\frac{B_{i}}{B_{U}}\right) \\
=\sum_{j=2}^{\infty}\left(\frac{1}{B_{j-1}}-\frac{1}{B_{j}}\right) \frac{\left(B_{j}-B_{i, j}\right)^{2} / B_{j-1}}{1+\left(B_{i, j-1}-B_{j-1}\right) / B_{j-1}}-\sum_{j=2}^{\infty}\left(\frac{1}{B_{j-1}}-\frac{1}{B_{j}}\right) \frac{\left(B_{j}-B_{i, j}\right)^{2} / B_{j-1}}{1+\left(B_{i, j-1}-B_{j-1}\right) / B_{j-1}}
\end{gathered}
$$

If $\frac{\left(B_{j}-B_{i, j}\right)^{2} / B_{j-1}}{1+\left(B_{i, j-1}-B_{j-1}\right) / B_{j-1}}>\frac{\left(B_{j}-B_{i, j}\right)^{2} / B_{j-1}}{1+\left(B_{i, j-1}-B_{j-1}\right) / B_{j-1}}$, then $\exp \left(\frac{s}{B}\right)-\frac{B_{i}}{B_{U}}>0$ and introduction of derivative security will increase the fraction of informed investors.

If $\frac{\left(B_{j}-B_{i, j}\right)^{2} / B_{j-1}}{1+\left(B_{i, j-1}-B_{j-1}\right) / B_{j-1}}<\frac{\left(B_{j}-B_{i, j}\right)^{2} / B_{j-1}}{1+\left(B_{i, j-1}-B_{j-1}\right) / B_{j-1}}$, then $\exp \left(\frac{s}{B}\right)-\frac{B_{i}}{B_{U}}<0$ and introduction of derivative security will decrease the fraction of informed investors. Following the proof the Proposition 4.7, we can get results in this proposition. 
Proof of Proposition 3.3. Price informativeness $I=\frac{\omega^{2} s^{2} q}{\gamma^{2}}$. It is obvious that $I$ is an increasing function of omega. Following Proposition 3.2, this proposition can be derived directly.

Proof of Proposition 3.4. (a)The expected asset price is $\bar{D}-\frac{\bar{X}}{B_{j}}$. Since $B=h+\omega s+\frac{\omega^{2} s^{2}}{\gamma^{2}} q+c$, thus $B$ is an increasing function of $\omega$ and then we can conclude that expected asset price is also an increasing function of $\omega$. (b) The market response to public information is $\frac{c}{B}$ which is a decreasing function of $\omega$. (c) The price change volatility is

$$
\operatorname{Var}(D-P)=\frac{1}{B}+\frac{\omega s+\gamma^{2} q^{-1}}{B^{2}}
$$

The derivative of $\operatorname{Var}(D-P)$ with $\omega$ is:

$$
-\frac{s+\frac{2 \omega s^{2}}{\gamma^{2}} q}{B^{2}}+\frac{s}{B^{2}}-\frac{2\left(\omega s+\gamma^{2} q^{-1}\right)}{B^{3}}\left(s+\frac{2 \omega s^{2}}{\gamma^{2}} q\right)<0
$$

So we can conclude that first derivative of $\operatorname{Var}(D-P)$ with $\omega$ is negative and thus the price change volatility is a decreasing function of $\omega$. Therefore, we can get the results in the proposition.

Proof of Proposition 3.5 and Lemma 3.3. As shown in the analysis, $V_{o}=\int_{0}^{\omega}\left|\left(B_{i}-B\right)\right| d i+$ $(1-\omega)\left|B-B_{U}\right|=2 \omega(1-\omega) s$. When $\omega \leq \frac{1}{2}, V_{o}$ is an increasing function of $\omega$. As proved in Lemma 4.1 , in $\left(C_{d 2}, C_{d 1}\right)$, the equilibrium fraction of

informed investors is a decreasing function of information acquisition cost and there is unique corresponding information acquisition $\operatorname{cost} C_{M}$ which induces the fraction of informed investors to be $\frac{1}{2}$. This means that when $C>C_{M}, V_{o}$ is a decreasing function of $C$; when $C<C_{M}, V_{o}$ is a increasing function of $C$. This completes the proof.

Proof of Proposition 4.1 and Lemma 4.1. We use backward induction to prove the linear price function and investors' demand. This means that we firstly prove that the $P_{j}, X_{i, j}$ and $X_{U, j}$ follows the proposition, and then we prove that $P_{j-1}, X_{i, j-1}$ and $X_{U, j-1}$ follows the proposition. In the economy of $T$ trading sessions (where $T=N$ or $N+M$ ), informed investor $i$ 's final wealth $W_{i, F}=W_{0}+X_{i, 1}\left(P_{2}-P_{1}\right)+X_{i, 2}\left(P_{3}-P_{2}\right)+X_{i, 3}\left(P_{4}-P_{3}\right)+\ldots . X_{i, T}\left(D-P_{T}\right)$ and liquidity suppliers' final wealth $W_{U, F}=W_{0}+X_{U, 1}\left(P_{2}-P_{1}\right)+X_{U, 2}\left(P_{3}-P_{2}\right)+X_{U, 3}\left(P_{4}-P_{3}\right)+\ldots . X_{U, T}\left(D-P_{T}\right)$ . We also have the dynamic of investors' wealth as: $W_{i, j}=W_{i, j-1}+X_{i, j-1}\left(P_{j}-P_{j-1}\right)$ and $W_{U, j}=W_{U, j-1}+X_{U, j-1}\left(P_{j}-P_{j-1}\right)$. 
At trading round $T$, informed investor $i$ 's information set $\mathcal{F}_{s, T}=\left\{s_{i}, s_{c, k}, P_{k} \quad k=1,2 \ldots . T\right\}$ and the conditional distribution of $D$ in their beliefs are

$$
\begin{aligned}
E\left(D \mid \mathcal{F}_{i, T}\right) & =\bar{D}+\frac{s\left(D-\bar{D}+\epsilon_{i}\right)+\frac{\omega^{2} s^{2}}{\gamma^{2}}\left(D-\bar{D}+\frac{\gamma}{\omega s} n\right)+\sum_{k=1}^{T} c_{k}\left(s_{c, k}-\bar{D}\right)}{h+s+\frac{\omega^{2} s^{2}}{\gamma^{2}}+\sum_{k=1}^{T} c_{k}} \\
\operatorname{Var}\left(D \mid \mathcal{F}_{i, T}\right) & =\frac{1}{h+s+\frac{\omega^{2} s^{2}}{\gamma^{2}}+\sum_{k=1}^{T} c_{k}}
\end{aligned}
$$

They try to maximize their utility over the final wealth:

$$
E V_{i, T}=\max _{X_{i, T}}-\exp \left[-\gamma\left\{W_{i, T}+X_{i, T}\left(D-P_{T}\right)\right\}\right]
$$

So informed investor $i$ 's optimal demand is: $X_{i, T}=\frac{E\left(D \mid \mathcal{F}_{i, T}\right)-P_{T}}{\gamma \operatorname{Var}\left(D \mid \mathcal{F}_{i, T}\right)}$. We substitute $X_{i, T}$ into the above equation, we have liquidity demanders' equivalent utility is:

$$
E V_{i, T}=-\exp \left[-\gamma\left\{W_{i, T-1}+\frac{\left[E\left(D \mid \mathcal{F}_{i, T}\right)-P_{T}\right]^{2}}{2 \gamma \operatorname{Var}\left(D \mid \mathcal{F}_{i, T}\right)}\right\}\right]
$$

Uninformed investors' information set $\mathcal{F}_{U, T}=\left\{s_{c, k}, P_{k} k=1,2 \ldots . T\right\}$ and the conditional distribution of $D$ in their beliefs are

$$
\begin{aligned}
E\left(D \mid \mathcal{F}_{U, T}\right) & =\bar{D}+\frac{\frac{\omega^{2} s^{2}}{\gamma^{2}}\left(D-\bar{D}+\frac{\gamma}{\omega s} n\right)+\sum_{k=1}^{T} c_{k}\left(s_{c, k}-\bar{D}\right)}{h+s+\frac{\omega^{2} s^{2}}{\gamma^{2}}+\sum_{k=1}^{T} c_{k}} \\
\operatorname{Var}\left(D \mid \mathcal{F}_{U, T}\right) & =\frac{1}{h+\frac{\omega^{2} s^{2}}{\gamma^{2}}+\sum_{k=1}^{T} c_{k}}
\end{aligned}
$$

They try to maximize their utility over the final wealth:

$$
E V_{U, T}=\max _{X_{U, T}}-\exp \left[-\gamma\left\{W_{D, T}+X_{U, T}\left(D-P_{T}\right)\right\}\right]
$$

So uninformed investors' optimal demand is: $X_{U, T}=\frac{E\left(D \mid \mathcal{F}_{U, T}\right)-P_{T}}{\gamma \operatorname{Var}\left(D \mid \mathcal{F}_{U, T}\right)}$. We substitute $X_{U, T}$ into the above equation, we have uninformed investors' equivalent utility is:

$$
E V_{U, T}=-\exp \left[-\gamma\left\{W_{U, T-1}+\frac{\left[E\left(D \mid \mathcal{F}_{U, T}\right)-P_{T}\right]^{2}}{2 \gamma \operatorname{Var}\left(D \mid \mathcal{F}_{U, T}\right)}\right\}\right]
$$

In the market clearing condition: $\int_{i=0}^{\omega} X_{i, T} d i+(1-\omega) X_{U, T}+n=\bar{X}$. We can get the price function as the description in the proposition.

Now we turn to the trading round $T-1$. Given the price and optimal demands in trading 
round $T-1$. For the informed investors, they maximize utility

$$
E V_{i, T-1}=-\max _{X_{i, T-1}} \exp \left[-\gamma\left\{W_{i, T-2}+X_{i, T-1}\left(P_{T}-P_{T-1}\right)+\frac{\left[E\left(D \mid \mathcal{F}_{i, T}\right)-P_{T}\right]^{2}}{2 \gamma \operatorname{Var}\left(D \mid \mathcal{F}_{i, T}\right)}\right\}\right]
$$

Let $B_{j}=h+\omega s+\frac{\omega^{2} s^{2}}{\gamma^{2}}+\sum_{k=1}^{j} c_{k}, K_{i, j}=h+s+\frac{\omega^{2} s^{2}}{\gamma^{2}}+\sum_{k=1}^{j} c_{k}$ and $K_{U, j}=h+\frac{\omega^{2} s^{2}}{\gamma^{2}}+\sum_{k=1}^{j} c_{k}$ In the conjecture price, $P_{T}=\frac{B_{T-1} P_{T-1}+c_{T} s_{c, T}}{B_{T}} \Rightarrow P_{T}-P_{T-1}=\frac{c_{T}\left(s_{c, T}-P_{T-1}\right)}{B_{T}}$

$$
\begin{aligned}
& E\left(D \mid \mathcal{F}_{i, T}\right)=\frac{B_{i, T-1} E\left(D \mid \mathcal{F}_{i, T-1}\right)+c_{T} s_{c, T}}{B_{i, T}} \\
& \Rightarrow E\left(D \mid \mathcal{F}_{i, T}\right)-P_{T}=\frac{B_{i, T-1} E\left(D \mid \mathcal{F}_{i, T-1}\right)+P_{T} B_{T}-B_{T-1} P_{T-1}}{B_{i, T}}-P_{T} \\
& =\left(\frac{B_{T}}{B_{i, T}}-1\right)\left(P_{T}-P_{T-1}\right)+\frac{B_{i, T-1}}{B_{i, T}}\left[E\left(D \mid \mathcal{F}_{i, T-1}\right)-P_{T-1}\right]
\end{aligned}
$$

So in informed investor $i$ 's belief: $E\left(P_{T}-P_{T-1} \mid \mathcal{F}_{i, T-1}\right)=\frac{c_{T}\left(E\left(D \mid \mathcal{F}_{i, T-1}\right)-P_{T-1}\right)}{B_{T}}$ and $\operatorname{Var}\left(P_{T}-\right.$ $\left.P_{T-1} \mid \mathcal{F}_{i, T-1}\right)=\frac{c_{T}^{2}\left(\frac{1}{B_{i, T-1}}+\frac{1}{c_{T}}\right)}{B_{T}^{2}}=\frac{c_{T} B_{i, T}}{B_{i, T-1} B_{T}^{2}}$

$$
\begin{aligned}
& -\max _{X_{i, T-1}} \exp \left[-\gamma\left\{W_{i, T-2}+X_{i, T-1}\left(P_{T}-P_{T-1}\right)\right.\right. \\
& +\frac{B_{i, T}\left(\frac{B_{T}}{B_{i, T}}-1\right)^{2}\left(P_{T}-P_{T-1}\right)^{2}}{2 \gamma} \\
& +\frac{B_{i, T}\left(\frac{B_{T}}{B_{i, T}}-1\right)\left(P_{T}-P_{T-1}\right) \frac{B_{i, T-1}}{B_{i, T}}\left[E\left(D \mid \mathcal{F}_{i, T-1}\right)-P_{T-1}\right]}{\gamma} \\
& \left.\left.\frac{B_{i, T} \frac{B_{i, T-1}^{2}}{B_{i, T}^{2}}\left[E\left(D \mid \mathcal{F}_{i, T-1}\right)-P_{T-1}\right]^{2}}{2 \gamma}\right\}\right] \\
& \Leftrightarrow-\max _{X_{d, \tau_{T-2}}} \frac{1}{\sqrt{1+B_{i, T}\left(\left(\frac{B_{T}}{B_{i, T}}-1\right)^{2} \frac{c_{T} B_{i, T}}{B_{i, T-1} B_{T}^{2}}\right.}} \exp \left[-\gamma\left\{W_{i, T-2}\right.\right. \\
& +\left(X_{i, T-1}+\frac{\left(\frac{B_{T}}{B_{i, T}}-1\right) B_{i, T-1}\left[E\left(D \mid \mathcal{F}_{i, T-1}\right)-P_{T-1}\right]}{\gamma}\right) \frac{c_{T}\left(E\left(D \mid \mathcal{F}_{i, T-1}\right)-P_{T-1}\right)}{B_{T}} \\
& +\frac{B_{i, T} \frac{B_{i, T-1}^{2}}{B_{i, T}^{2}}\left[E\left(D \mid \mathcal{F}_{i, T-1}\right)-P_{T-1}\right]^{2}}{2 \gamma} \\
& {\left[\gamma X_{i, T-1}+\left(\frac{B_{T}}{B_{i, T}}-1\right) B_{i, T-1}\left[E\left(D \mid \mathcal{F}_{i, T-1}\right)-P_{T-1}\right]\right.} \\
& -\frac{1}{2} \frac{\left.+B_{i, T}\left(\frac{B_{T}}{B_{i, T}}-1\right)^{2} \frac{c_{T}\left(E\left(D \mid \mathcal{F}_{i, T-1}\right)-P_{T-1}\right)}{B_{T}}\right]^{2}}{\gamma\left(1+B_{i, T}\left(\frac{B_{T}}{B_{i, T}}-1\right)^{2} \frac{c_{T} B_{i, T}}{B_{i, T-1} B_{T}^{2}}\right)} \\
& \left.\left.* \frac{c_{T} B_{i, T}}{B_{i, T-1} B_{T}^{2}}\right\}\right]
\end{aligned}
$$

FOC, we have:

$$
\begin{gathered}
\frac{c_{T}\left(E\left(D \mid \mathcal{F}_{i, T-1}\right)-P_{T-1}\right)}{B_{T}}-\frac{\frac{c_{T} B_{i, T}}{B_{i, T-1} B_{T}^{2}}}{1+B_{i, T}\left(\frac{B_{T}}{B_{i, T}}-1\right)^{2} \frac{c_{T} B_{i, T}}{B_{i, T-1} B_{T}^{2}}} \\
\times\left\{\left[\gamma \left(X_{i, T-1}+\left(\frac{B_{T}}{B_{i, T}}-1\right) B_{i, T-1}\left[E\left(D \mid \mathcal{F}_{i, T-1}\right)-P_{T-1}\right]\right.\right.\right. \\
\left.\left.+B_{i, T}\left(\frac{B_{T}}{B_{i, T}}-1\right)^{2} \frac{c_{T}\left(E\left(D \mid \mathcal{F}_{i, T-1}\right)-P_{T-1}\right)}{B_{T}}\right]\right\} \\
=0 \\
\Rightarrow \gamma\left(X_{i, T-1}+\left(\frac{B_{T}}{B_{i, T}}-1\right) B_{i, T-1}\left[E\left(D \mid \mathcal{F}_{i, T-1}\right)-P_{T-1}\right]+B_{i, T}\left(\frac{B_{T}}{B_{i, T}}-1\right)^{2} \frac{c_{T}\left(E\left(D \mid \mathcal{F}_{i, T-1}\right)-P_{T-1}\right)}{B_{T}}\right] \\
=\frac{\left(E\left(D \mid \mathcal{F}_{i, T-1}\right)-P_{T-1} B_{i, T-1} B_{T}\right.}{B_{i, T}}\left(1+B_{i, T}\left(\frac{B_{T}}{B_{i, T}}-1\right)^{2} \frac{c_{T} B_{i, T}}{B_{i, T-1} B_{T}^{2}}\right)
\end{gathered}
$$


$\Rightarrow X_{i, T-2}=\frac{\left(E\left(D \mid \mathcal{F}_{i, T-1}\right)-P_{T-1}\right) B_{i, T-1}}{\gamma}$ Since $\operatorname{Var}\left(D \mid \mathcal{F}_{i, T-1}\right)=\frac{1}{B_{i, T-1}}$. We have proved that $X_{i, T-2}$ is the same as the proposition.

Then we put $X_{i, T-1}$ into the utility function, we have:

$$
E V_{i, T-1}=\begin{gathered}
-\frac{1}{\sqrt{1+\frac{{ }^{{ }^{T} T}\left(B_{T}-B_{i, T}\right)^{2}}{B_{i, T-1} B_{T}^{2}}}} \\
\times \exp \left[-\gamma\left\{W_{i, T-2}+\frac{\left[E\left(D \mid \mathcal{F}_{i, T-1}\right)-P_{T-1}\right]^{2}}{2 \gamma \operatorname{Var}\left(D \mid \mathcal{F}_{i, T-1}\right)}\right\}\right]
\end{gathered}
$$

For the uninformed investors' demands, we can follow the same methodology and just replace $B_{i, j}$ with $B_{U, j}$. And we have the uninformed investors' demand $X_{U, T-1}=\frac{\left(E\left(D \mid \mathcal{F}_{U, T-1}\right)-P_{T-1}\right) B_{U, T-1}}{\gamma}$ Since $\operatorname{Var}\left(D \mid \mathcal{F}_{U, T-1}\right)=\frac{1}{B_{U, T-1}}$. We have proved that $X_{s, \tau_{T-2}}$ is the same as the proposition. The market clearing condition, we can get the price function $P_{1, \tau_{T-2}}$ as the proposition. We can have liquidity suppliers' expected utility is

$$
E V_{U, T-1}=-\frac{1}{\sqrt{1+\frac{c_{T}\left(B_{T}-B_{U, T}\right)^{2}}{B_{U, T-1} B_{T}^{2}}}} \exp \left[-\gamma\left\{W_{U, T-2}+\frac{\left[E\left(D \mid \mathcal{F}_{U, T-1}\right)-P_{T-1}\right]^{2}}{2 \gamma \operatorname{Var}\left(D \mid \mathcal{F}_{U, T-1}\right)}\right\}\right]
$$

Proceeding recursively, we can get the price functions and demands as the propositions. This complete the proof of the proposition.

For the lemma, we proceed recursively and can get that:

$$
\begin{aligned}
& -\exp \left[-\gamma\left\{W_{0}+\frac{\left[E\left(D \mid \mathcal{F}_{i, 1}\right)-P_{1}\right]^{2}}{2 \gamma \operatorname{Var}\left(D \mid \mathcal{F}_{i, 1}\right)}\right\}\right] \quad-\exp \left[-\gamma W_{0}-\frac{\gamma \bar{X}^{2}}{2 B_{0}^{2} \operatorname{Var}\left(D-P_{0}\right)}\right] \\
& E V_{i}=\quad \times \prod_{j=1}^{j=T} \frac{1}{\sqrt{1+\frac{c_{j}\left(B_{j}-B_{i, j}\right)^{2}}{B_{i, j-1} B_{j}^{2}}}} \quad=\times \frac{1}{\sqrt{\operatorname{Var}\left(D-P_{1}\right) B_{i, 1}}} \prod_{j=1}^{j=T} \frac{1}{\sqrt{1+\frac{c_{j}\left(B_{j}-B_{i, j}\right)^{2}}{B_{i, j-1} B_{j}^{2}}}}
\end{aligned}
$$

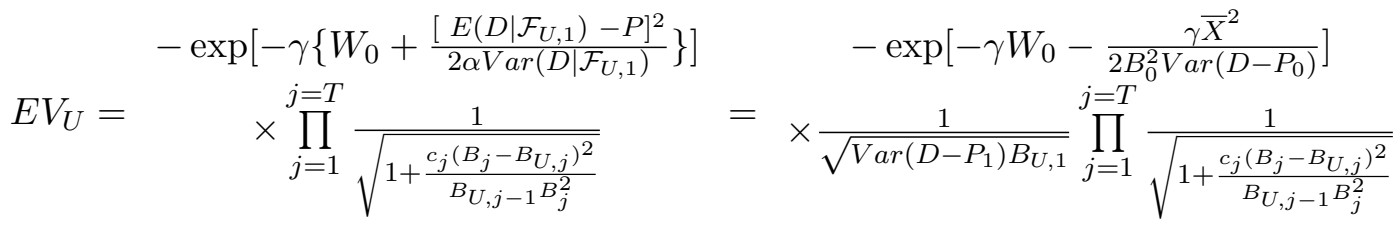

\section{Proof of Proposition 4.2.}

$$
\begin{gathered}
\ln (G)=\ln \left(1+\frac{s}{h+\frac{\omega^{2} s^{2}}{\gamma^{2}}+c_{1} z}\right)+\sum_{j=2}^{N} \ln \left(1+\frac{c_{j} z\left(B_{j}-B_{i, j}\right)^{2}}{B_{i, j-1} B_{j}^{2}}\right)-\sum_{j=2}^{N} \ln \left(1+\frac{c_{j} z\left(B_{j}-B_{U, j}\right)^{2}}{B_{U, j-1} B_{j}^{2}}\right) \\
=\ln \left(1+\frac{s}{h+\frac{\omega^{2} s^{2}}{\gamma^{2}}+c_{1} z}\right)+\sum_{j=2}^{N} \frac{c_{j} z\left(B_{j}-B_{i, j}\right)^{2}}{B_{i, j-1} B_{j}^{2}}-\sum_{j=2}^{N} \frac{c_{j} z\left(B_{j}-B_{U, j}\right)^{2}}{B_{U, j-1} B_{j}^{2}}
\end{gathered}
$$


In the above equation, we have

$$
\begin{gathered}
\frac{c_{j} z\left(B_{j}-B_{i, j}\right)^{2}}{B_{i, j-1} B_{j}^{2}}=\left(\frac{1}{B_{j-1}}-\frac{1}{B_{j}}\right) \frac{\left(B_{j}-B_{i, j}\right)^{2} / B_{j-1}}{1+\left(B_{i, j-1}-B_{j-1}\right) / B_{j-1}} \frac{B_{j-1}}{B_{j}}= \\
=\left(\frac{1}{B_{j-1}}-\frac{1}{B_{j}}\right) \frac{\left(B_{j}-B_{i, j}\right)^{2} / B_{j-1}}{1+\left(B_{i, j-1}-B_{j-1}\right) / B_{j-1}}-\left(\frac{1}{B_{j-1}}-\frac{1}{B_{j}}\right)^{2} \frac{\left(B_{j}-B_{i, j}\right)^{2}}{1+\left(B_{i, j-1}-B_{j-1}\right) / B_{j-1}} \\
=\left(\frac{1}{B_{j-1}}-\frac{1}{B_{j}}\right) \frac{\left(B_{j}-B_{i, j}\right)^{2} / B_{j-1}}{1+\left(B_{i, j-1}-B_{j-1}\right) / B_{j-1}}
\end{gathered}
$$

Therefore,

$$
\begin{gathered}
\sum_{j=2}^{T}\left(\frac{1}{B_{j-1}}-\frac{1}{B_{j}}\right) \frac{\left(B_{j}-B_{i, j}\right)^{2} / B_{j-1}}{1+\left(B_{i, j-1}-B_{j-1}\right) / B_{j-1}} \\
=\int_{\frac{1}{B_{T}}}^{\frac{1}{B_{1}}} \frac{(1-\omega)^{2} s^{2} t}{1+(1-\omega) s t} d t \\
=(1-\omega) s\left(\frac{1}{B_{1}}-\frac{1}{B_{T}}\right)-\left[\ln \left(1+\frac{(1-\omega) s}{B_{1}}\right)-\ln \left(1+\frac{(1-\omega) s}{B_{T}}\right)\right]
\end{gathered}
$$

Similarly, we will have

$\sum_{j=2}^{T}\left(\frac{1}{B_{j-1}}-\frac{1}{B_{j}}\right) \frac{\left(B_{j}-B_{U, j}\right)^{2} / B_{j-1}}{1+\left(B_{U, j-1}-B_{j-1}\right) / B_{j-1}}=\int_{\frac{1}{B_{T}}}^{\frac{1}{B_{1}}} \frac{\omega^{2} s^{2} t}{1-\omega s t} d t=-\omega s\left(\frac{1}{B_{1}}-\frac{1}{B_{T}}\right)-\left[\ln \left(1-\frac{\omega s}{B_{1}}\right)-\ln \left(1-\frac{\omega s}{B_{T}}\right)\right]$

Therefore, $\ln (G)=s\left(\frac{1}{B_{1}}-\frac{1}{B_{T}}\right)+\ln \left(1+\frac{s}{B_{U, T}}\right)$ and it is obvious that $\ln (G)$ is a decreasing function of $\omega$

Proof of Corollary 4.1 . In the equilibrium, investors should break even the gain from information acquisition and cost. If $G(0) \leq \exp (2 \gamma C)$, the equilibrium fraction of informed investors $\omega^{*}=0$. If $G(0)>\exp (2 \gamma C)>G(1)$, the equilibrium fraction of informed investors $\omega^{*} \in(0,1)$ which satisfies $G\left(\omega^{*}\right)=\exp (2 \gamma C)$. If $\exp (2 \gamma C) \leq G(1)$,the equilibrium fraction of informed investors $\omega^{*}=1$.. Therefore, we can get the corollary. And $C_{1}$ satisfy $G(0)=\exp \left(2 \gamma C_{1}\right)$ and $C_{2}$ satisfy $G(1)=\exp \left(2 \gamma C_{2}\right)$. Since $G$ is a decreasing function of $\omega$, it is obvious that $\omega^{*}$ is a decreasing function with $C$ when $C_{2}<C<C_{1}$

Proof of Corollary 4.3 . In the equilibrium, investors should break even the gain from information acquisition and cost. If $G(0) \leq \exp (2 \gamma C)$, the equilibrium fraction of informed investors $\omega^{*}=0$. If $G(0)>\exp (2 \gamma C)>G(1)$, the equilibrium fraction of informed investors $\omega^{*} \in(0,1)$ which satisfies $G\left(\omega^{*}\right)=\exp (2 \gamma C)$. If $\exp (2 \gamma C) \leq G(1)$,the equilibrium fraction of informed investors $\omega^{*}=1$.. Therefore, we can get the corollary. And $F_{1}$ satisfy $G(0)=\exp (2 \gamma C)$ and $F_{2}$ satisfy $G(1)=\exp (2 \gamma C)$. Since $G$ is a decreasing function of $\omega$, it is obvious that $\omega^{*}$ is a decreasing function with $F_{k}$ when $F_{2}<F_{k}<F_{1}$

Proof of Proposition 4.3 and Lemma 4.2 . There are several steps to prove that the proposition holds. 
Step 1: Following the similar procedure in the proof of Proposition 4.1, we know that $\int_{0}^{\infty} P_{C G, j} d G+\int_{-\infty}^{0} P_{P G, j} d G=\frac{1}{2}\left(\frac{1}{B_{j}}+P_{j}^{2}\right)$

Step 2: We want to prove that the expected utility of informed investors and uninformed are as shown in the Lemma 5.1 given the proposed equilibrium in the Proposition 5.1. Given the equilibrium in Proposition 5.1, we have

$$
\begin{gathered}
W_{i, j+1}=W_{i, j}+\left[\frac{B_{i, j}}{\gamma}\left(E\left(D \mid \mathcal{F}_{i, j}\right)-P_{j}\right)-\frac{1}{\gamma}\left(B_{j}-B_{i, j}\right) P_{j}\right]\left(P_{j+1}-P_{j}\right) \\
+\frac{B_{j}-B_{i, j}}{2 \gamma}\left(\frac{1}{B_{j+1}}+P_{j+1}^{2}-\frac{1}{B_{j}}-P_{j}^{2}\right) \\
=W_{i, j}+\frac{B_{i, j}}{\gamma}\left(E\left(D \mid \mathcal{F}_{i, j}\right)-P_{j}\right)\left(P_{j+1}-P_{j}\right)+\frac{B_{j}-B_{i, j}}{2 \gamma}\left(P_{j+1}-P_{j}\right)^{2} \\
+\frac{B_{j}-B_{i, j}}{2 \gamma}\left(\frac{1}{B_{j+1}}-\frac{1}{B_{j}}\right)
\end{gathered}
$$

where $B_{T+1}=+\infty$ (because final payoff is realized and investors have infinite information precision) and $P_{T+1}=D$

We can use backward induction to prove that

$$
E V_{i, j}=-\frac{1}{\sqrt{\frac{B_{j}}{B_{i}, j}}} \exp \left[-\gamma W_{i, j}-\frac{\left[E\left(D \mid \mathcal{F}_{i, j}\right)-P_{j}\right]^{2}}{2 \operatorname{Var}\left(D \mid \mathcal{F}_{i, j}\right)}+\frac{B_{j}-B_{i, j}}{2} \frac{1}{B_{j}}\right]
$$

For last period, this is true following the proof of Proposition 4.1. Now we assume that this holds for period $j+1$, for period $j$, we have:

$$
E V_{i, j}=-\frac{1}{\sqrt{\frac{B_{j+1}}{B_{i}, j+1}}} E\left\{\exp \left[-\gamma W_{i, j+1}-\frac{\left[E\left(D \mid \mathcal{F}_{i, j+1}\right)-P_{j+1}\right]^{2}}{2 \operatorname{Var}\left(D \mid \mathcal{F}_{i, j+1}\right)}+\frac{B_{j+1}-B_{i, j+1}}{2} \frac{1}{B_{j+1}}\right]\right\}
$$

As the proof the Proposition 3.1, we have: $E\left(D \mid \mathcal{F}_{i, j+1}\right)-P_{j+1}=\left(\frac{B_{j+1}}{B_{i, j+1}}-1\right)\left(P_{j+1}-P_{j}\right)+$ $\frac{B_{i, j}}{B_{i, j+1}}\left[E\left(D \mid \mathcal{F}_{i, j}\right)-P_{j}\right], E\left(P_{j+1}-P_{j} \mid \mathcal{F}_{i, j}\right)=\frac{c_{J+1}\left(E\left(D \mid \mathcal{F}_{i, j}\right)-P_{j}\right)}{B_{j+1}}$ and $\operatorname{Var}\left(P_{j+1}-P_{j} \mid \mathcal{F}_{i, j}\right)=\frac{c_{j+1} B_{i, j+1}}{B_{i, j} B_{j+1}^{2}}$

So we substitute them into $E V_{i, j}$, we have:

$$
E V_{i, j}=-\frac{1}{\sqrt{\frac{B_{j}}{B_{i, j}}}} E\left\{\exp \left[-\gamma W_{i, j}-\frac{\left[E\left(D \mid \mathcal{F}_{i, j+1}\right)-P_{j+1}\right]^{2}}{2 \gamma \operatorname{Var}\left(D \mid \mathcal{F}_{i, j+1}\right)}+\frac{B_{j}-B_{i, j}}{2} \frac{1}{B_{j}}\right]\right\}
$$

The ex-ante expected utility for

$$
\begin{gathered}
E V_{i}=-\exp \left[-\gamma W_{0}-\frac{\bar{X}^{2}}{2 \gamma B^{2} \operatorname{Var}(D-P)}\right] \times \frac{1}{\sqrt{\operatorname{Var}(D-P) B_{i}}} \\
E V_{U}=-\exp \left[-\gamma W_{0}-\frac{\bar{X}^{2}}{2 \gamma B^{2} \operatorname{Var}(D-P)}\right] \times \frac{1}{\sqrt{\operatorname{Var}(D-P) B_{U}}}
\end{gathered}
$$


Step 3: to simplify the analysis, we want to prove that final wealth $W_{i, F}=W_{i, j}+$ $\frac{B_{i, j}}{\gamma}\left(E\left(D \mid \mathcal{F}_{i, j}\right)-P_{j}\right)\left(D-P_{j}\right)+\frac{B_{j}-B_{i, j}}{2 \gamma}\left[\left(D-P_{j}\right)^{2}-\frac{1}{B_{j}}\right]$

Here, we use backward induction to prove that. For the final period $T$, this is true following the proof of Proposition 4.1. We assume that this is true for period $j+1$. Then we would like to prove this is true for period $j . W_{i, F}=W_{i, j}+\frac{B_{i, j}}{\gamma}\left(E\left(D \mid \mathcal{F}_{i, j}\right)-P_{j}\right)\left(P_{j+1}-P_{j}\right)+\frac{B_{j}-B_{i, j}}{2 \gamma}\left[\left(P_{j+1}-\right.\right.$ $\left.\left.P_{j}\right)^{2}+\frac{1}{B_{j+1}}-\frac{1}{B_{j}}\right]+\frac{B_{i, j+1}}{\gamma}\left(E\left(D \mid \mathcal{F}_{i, j+1}\right)-P_{j+1}\right)\left(D-P_{j+1}\right)+\frac{B_{j+1}-B_{i, j+1}}{2 \gamma}\left[\left(D-P_{j+1}\right)^{2}-\frac{1}{B_{j+1}}\right]$

(Since $\left.E\left(D \mid \mathcal{F}_{i, j+1}\right)-P_{j+1}=\left(\frac{B_{j+1}}{B_{i, j+1}}-1\right)\left(P_{j+1}-P_{j}\right)+\frac{B_{i, j}}{B_{i, j+1}}\left[E\left(D \mid \mathcal{F}_{i, j}\right)-P_{j}\right]\right)$

$=W_{i, j}+\frac{B_{i, j}}{\gamma}\left(E\left(D \mid \mathcal{F}_{i, j}\right)-P_{j}\right)\left(P_{j+1}-P_{j}\right)+\frac{B_{j}-B_{i, j}}{2 \gamma}\left(P_{j+1}-P_{j}\right)^{2}+\frac{B_{i, j+1}}{\gamma}\left[\left(\frac{B_{j+1}}{B_{i, j+1}}-1\right)\left(P_{j+1}-\right.\right.$ $\left.\left.P_{j}\right)+\frac{B_{i, j}}{B_{i, j+1}}\left[E\left(D \mid \mathcal{F}_{i, j}\right)-P_{j}\right]\right]\left(D-P_{j+1}\right)+\frac{B_{j+1}-B_{i, j+1}}{2 \gamma}\left[\left(D-P_{j+1}\right)^{2}-\frac{B_{j}-B_{i, j}}{2 \gamma B_{j}}\right.$

$=W_{i, j}+\frac{B_{i, j}}{\gamma}\left(E\left(D \mid \mathcal{F}_{i, j}\right)-P_{j}\right)\left(D-P_{j}\right)+\frac{B_{j}-B_{i, j}}{2 \gamma}\left[\left(P_{j+1}-P_{j}\right)^{2}+2\left(P_{j+1}-P_{j}\right)\left(D-P_{j+1}\right)+(D-\right.$ $\left.\left.P_{j+1}\right)^{2}\right]-\frac{B_{j}-B_{i, j}}{2 \gamma B_{j}}$

$$
=W_{i, j}+\frac{B_{i, j}}{\gamma}\left(E\left(D \mid \mathcal{F}_{i, j}\right)-P_{j}\right)\left(D-P_{j}\right)+\frac{B_{j}-B_{i, j}}{2 \gamma}\left[\left(D-P_{j}\right)^{2}-\frac{1}{B_{j}}\right]
$$

Step 4: we now prove that Euler conditions hold for every period. We also use backward induction to prove it. Euler conditions hold for the final period following the proof of Proposition 4.1. We assume that Euler conditions is true for the period $j+1$. This indicates that the proposed demands and price functions take the forms in the proposition.

We need to prove that

$$
\begin{aligned}
E\left[\left(P_{j+1}-P_{j}\right) \exp \left(-\gamma W_{i, j+1}\right) \mid \mathcal{F}_{i, j}\right] & =0 \\
E\left[\left(P_{C G, j+1}-P_{C G, j}\right) \exp \left(-\gamma W_{i, j+1}\right) \mid \mathcal{F}_{i, j}\right] & =0 \\
E\left[\left(P_{P G, j+1}-P_{P G, j}\right) \exp \left(-\gamma W_{i, j+1}\right) \mid \mathcal{F}_{i, j}\right] & =0
\end{aligned}
$$

Following Cao and Ou-Yang (2009), we have

$$
\begin{gathered}
P_{j+1} \exp \left(-\gamma W_{i, j+1}\right)=E\left[D \exp \left(-\gamma W_{i, F}\right) \mid \mathcal{F}_{i, j}\right] \quad \exp \left(-\gamma W_{i, j+1}\right)=E\left[\exp \left(-\gamma W_{i, F}\right) \mid \mathcal{F}_{i, j}\right] \\
P_{C G, j+1} \exp \left(-\gamma W_{i, j+1}\right)=E\left[(D-G)^{+} \exp \left(-\gamma W_{i, F}\right) \mid \mathcal{F}_{i, j}\right] \\
P_{P G, j+1} \exp \left(-\gamma W_{i, j+1}\right)=E\left[(G-D)^{+} \exp \left(-\gamma W_{i, F}\right) \mid \mathcal{F}_{i, j}\right]
\end{gathered}
$$

This means that we need to prove that: 


$$
\begin{gathered}
E\left[P_{j} \exp \left(-\gamma W_{i, j+1}\right) \mid \mathcal{F}_{i, j}\right]=E\left[P_{j+1} \exp \left(-\gamma W_{i, j+1}\right) \mid \mathcal{F}_{i, j}\right] \\
=E\left[D \exp \left(-\gamma W_{i, F}\right) \mid \mathcal{F}_{i, j}\right] \\
=E\left[D \operatorname { e x p } \left(-\gamma\left(W_{i, j}+\frac{B_{i, j}}{\gamma}\left(E\left(D \mid \mathcal{F}_{i, j}\right)-P_{j}\right)\left(D-P_{j}\right)\right.\right.\right. \\
\left.\left.\left.+\frac{B_{j}-B_{i, j}}{2 \gamma}\left[\left(D-P_{j}\right)^{2}-\frac{1}{B_{j}}\right]\right)\right) \mid \mathcal{F}_{i, j}\right]
\end{gathered}
$$

and

$$
\begin{gathered}
E\left[P_{C G, j} \exp \left(-\gamma W_{i, j+1}\right) \mid \mathcal{F}_{i, j}\right]=E\left[P_{C G, j+1} \exp \left(-\gamma W_{i, j+1}\right) \mid \mathcal{F}_{i, j}\right] \\
=E\left[(D-G)^{+} \exp \left(-\gamma W_{i, F}\right) \mathcal{F}_{i, j}\right] \\
=E\left[(D-G)^{+}\right. \\
\quad \exp \left(-\gamma\left(W_{i, j}+\frac{B_{i, j}}{\gamma}\left(E\left(D \mid \mathcal{F}_{i, j}\right)-P_{j}\right)\left(D-P_{j}\right)\right.\right. \\
\left.\left.\left.+\frac{B_{j}-B_{i, j}}{2 \gamma}\left[\left(D-P_{j}\right)^{2}-\frac{1}{B_{j}}\right]\right)\right) \mid \mathcal{F}_{i, j}\right]
\end{gathered}
$$

and

$$
\begin{gathered}
E\left[P_{P G, j} \exp \left(-\gamma W_{i, j+1}\right) \mid \mathcal{F}_{i, j}\right]=E\left[P_{P G, j+1} \exp \left(-\gamma W_{i, j+1}\right) \mid \mathcal{F}_{i, j}\right] \\
=E\left[(G-D)^{+} \exp \left(-\gamma W_{i, F}\right) \mathcal{F}_{i, j}\right] \\
=E\left[(G-D)^{+}\right. \\
\quad \exp \left(-\gamma\left(W_{i, j}+\frac{B_{i, j}}{\gamma}\left(E\left(D \mid \mathcal{F}_{i, j}\right)-P_{j}\right)\left(D-P_{j}\right)\right.\right. \\
\left.\left.\left.+\frac{B_{j}-B_{i, j}}{2 \gamma}\left[\left(D-P_{j}\right)^{2}-\frac{1}{B_{j}}\right]\right)\right) \mid \mathcal{F}_{i, j}\right]
\end{gathered}
$$

The above three equations take similar forms in the proof the Proposition 4.1. Following the similar procedures, the above equations hold for period $j$. This completes the proof.

Proof of Proposition 4.4 . Following proof or Proposition 3.2, the gain of information acquisition without options is $\ln (G)=s\left(\frac{1}{B_{1}}-\frac{1}{B_{T}}\right)+\ln \left(1+\frac{s}{B_{U, T}}\right)$. When there are infinite trading periods, the aggregate information precision of public information goes to infinity. That is $B_{T} \rightarrow \infty$ and $B_{U, T} \rightarrow \infty$, then $\ln (G) \rightarrow \frac{s}{B_{1}}$ which is the gain of information acquisition with options. This indicates that the gain of information acquisition with options is equivalent to the gain of information acquisition with infinite trading periods (This is consistent with the argument in Brennan and Cao (1996)).

Following proof of Proposition 3.3, we know that the gain of information acquisition from additional one trading period for informed investors is higher than uninformed investors when information acquisition cost $C$ is higher than $C_{4}$ and the gain of information acquisition from additional one trading period for uninformed investors is higher than informed investors when information acquisition cost $C$ is smaller than $C_{3}$. Following the same logic in Proposition 3.3, we complete the proof of this proposition.

Proof of Proposition 4.5. Price reaction to public information in trading session $j$ is $\frac{c_{j} z}{B_{j}}$ which is decreasing function of omega. Then this result can be directly derived. 
Proof of Proposition 4.6. Step 1: we characterize $F_{3}$ and $F_{4}$.

when $\omega>\frac{1}{2}, \quad \operatorname{since} \frac{c_{j} z\left(B_{j}-B_{i, j}\right)^{2}}{B_{i, j-1} B_{j}^{2}} /\left(\frac{c_{j} z\left(B_{j}-B_{U, j}\right)^{2}}{B_{U, j-1} B_{j}^{2}}\right)=\frac{(1-\omega)^{2} B_{U, j-1}}{\omega^{2} B_{i, j-1}}<1, \quad$ then $\prod_{j=K+1}^{j=L} \frac{1+\frac{c_{j} z\left(B_{j}-B_{i, j}\right)^{2}}{B_{i, j-1} B_{j}^{2}}}{1+\frac{c_{j} z\left(B_{j}-B_{U, j}\right)^{2}}{B_{U, j-1} B_{j}^{2}}}<1$

when $\omega<\frac{1}{1+\sqrt{1+\frac{s}{h}}}$, since $\frac{(1-\omega)^{2}}{\omega^{2}}>1+\frac{s}{h}>\frac{B_{i, j-1}}{B_{U, j-1}}$, then $\prod_{j=K+1}^{j=L} \frac{1+\frac{c_{j}\left(B_{j}-B_{i, j}\right)^{2}}{B_{i, j-1} B_{j}^{2}}}{1+\frac{c_{j}\left(B_{j}-B_{U, j}\right)^{2}}{B_{U, j-1} B_{j}^{2}}}>1$.

Since $G$ is a decreasing function of $\omega$, there exist $F_{3}$ which satisfies $G\left(\frac{1}{2}, F_{3}\right)=\exp (2 \gamma C)$ and $F_{4}$ which satisfies $G\left(\frac{1}{1+\sqrt{1+\frac{s}{h}}}, F_{4}\right)=\exp (2 \gamma C)$. When $F_{K}>F_{4}, \omega^{*}$ is smaller than $\frac{1}{1+\sqrt{1+\frac{s}{h}}}$ and thus $\prod_{j=K+1}^{j=L} \frac{1+\frac{c_{j}\left(B_{j}-B_{i, j}\right)^{2}}{B_{i, j-1} B_{j}^{2}}}{1+\frac{c_{j}\left(B_{j}-B_{U, j}\right)^{2}}{B_{U, j-1} B_{j}^{2}}}>1$. Since $G\left(\omega^{*}, F_{K}\right)=\exp (2 \gamma C)$ in the case with $K$ trading sessions, $G\left(\omega^{*}\right) * \prod_{j=K+1}^{j=L} \frac{1+\frac{c_{j}\left(B_{j}-B_{i, j}\right)^{2}}{B_{i, j-1} B_{j}^{2}}}{1+\frac{c_{j}\left(B_{j}-B_{U, j}\right)^{2}}{B_{U, j-1} B_{j}^{2}}}>\exp (2 \gamma C)$. It is obvious that the equilibrium fraction of informed investors in the case with additional trading sessions is higher than $\omega^{*}$.

When $F_{K}<F_{3}$, we can get the opposite conclusion following the similar logic.

Step 2: we study option market's effects on asset pricing for different public information precision (a)The expected asset price is $\bar{D}-\frac{\bar{X}}{B_{j}}$. Since $B_{j}=h+\omega s+\frac{\omega^{2} s^{2}}{\gamma^{2}}+\sum_{k=1}^{j} c_{k}$, thus $B_{j}$ is an increasing function of $\omega$ and then we can conclude that expected asset price is also an increasing function of $\omega$.

(b) The market response to public information is $\frac{c_{k}}{B_{j}}$ which is a decreasing function of $\omega$.

(c) The price change volatility is

$$
\begin{gathered}
\operatorname{Var}\left(P_{j+1}-P_{j}\right)=\frac{c_{j+1}^{2}}{B_{j+1}^{2}} \operatorname{Var}\left(s_{c, j+1}-P_{j}\right) \\
=\frac{c_{j+1}^{2}}{B_{j+1}^{2}}\left[\frac{1}{c_{j+1}}+\operatorname{Var}\left(D-P_{j}\right)\right]=\frac{1}{B_{j}}-\frac{1}{B_{j+1}} \\
+\frac{c_{j+1}^{2}}{B_{j}^{2} B_{j+1}^{2}}\left(\omega s+\frac{\gamma^{2}}{q}\right) .
\end{gathered}
$$

The derivative of $\operatorname{Var}\left(P_{j+1}-P_{j}\right)$ with $\omega$ is:

$$
\begin{gathered}
-\frac{c_{j+1}}{B_{j}^{2} B_{j+1}}\left(s+2 \frac{\omega s^{2}}{\gamma^{2}}\right)-\frac{c_{j+1}}{B_{j} B_{j+1}^{2}}\left(s+2 \frac{\omega s^{2}}{\gamma^{2}}\right)+\frac{c_{j+1}^{2} s}{B_{j}^{2} B_{j+1}^{2}} \\
-\frac{2 c_{j+1}^{2}}{B_{j}^{3} B_{j+1}^{2}}\left(\omega s+\frac{\gamma^{2}}{q}\right)\left(s+2 \frac{\omega s^{2}}{\gamma^{2}}\right)-\frac{2 c_{j+1}^{2}}{B_{j}^{2} B_{j+1}^{3}}\left(\omega s+\frac{\gamma^{2}}{q}\right)\left(s+2 \frac{\omega s^{2}}{\gamma^{2}}\right) .
\end{gathered}
$$

since

$$
-\frac{c_{j+1} s}{B_{j}^{2} B_{j+1}}-\frac{c_{j+1} s}{B_{j} B_{j+1}^{2}}+\frac{c_{j+1}^{2} s}{B_{j}^{2} B_{j+1}^{2}}<0
$$


So we can conclude that first derivative of $\operatorname{Var}\left(P_{j+1}-P_{j}\right)$ with $\omega$ is negative and thus the price change volatility is a decreasing function of $\omega$.

Therefore, we can get the results in the proposition.

Proof of Proposition 4.7 . There are several steps:

Step 1: we characterize $C_{3}$ and $C_{4}$ and effects of additional trading opportunities on information acquisition. When $\omega>\frac{1}{2}$, since $\frac{c_{j} z\left(B_{j}-B_{i, j}\right)^{2}}{B_{i, j-1} B_{j}^{2}} /\left(\frac{c_{j} z\left(B_{j}-B_{U, j}\right)^{2}}{B_{U, j-1} B_{j}^{2}}\right)=\frac{(1-\omega)^{2} B_{U, j-1}}{\omega^{2} B_{i, j-1}}<1$, then $\prod_{j=K+1}^{j=L} \frac{1+\frac{c_{j} z\left(B_{j}-B_{i, j}\right)^{2}}{B_{i, j-1} B_{j}^{2}}}{1+\frac{c_{j} z\left(B_{j}-B_{U, j}\right)^{2}}{B_{U, j-1} B_{j}^{2}}}<1$

when $\omega<\frac{1}{1+\sqrt{1+\frac{s}{h}}}$, since $\frac{(1-\omega)^{2}}{\omega^{2}}>1+\frac{s}{h}>\frac{B_{i, j-1}}{B_{U, j-1}}$, then $\prod_{j=K+1}^{j=L} \frac{1+\frac{c_{j}\left(B_{j}-B_{i, j}\right)^{2}}{B_{i, j-1} B_{j}^{2}}}{1+\frac{c_{j}\left(B_{j}-B_{U, j}\right)^{2}}{B_{U, j-1} B_{j}^{2}}}>1$.

Since $G$ is a decreasing function of $\omega$, there exist $C_{3}$ which satisfies $G\left(\frac{1}{2}\right)=\exp \left(2 \gamma C_{3}\right)$ and $C_{4}$ which satisfies $G\left(\frac{1}{1+\sqrt{1+\frac{s}{h}}}\right)=\exp \left(2 \gamma C_{4}\right)$. When $C>C_{4}, \omega^{*}$ is smaller than $\frac{1}{1+\sqrt{1+\frac{s}{h}}}$ and thus $\prod_{j=K+1}^{j=L} \frac{1+\frac{c_{j}\left(B_{j}-B_{i, j}\right)^{2}}{B_{i, j-1} B_{j}^{2}}}{1+\frac{c_{j}\left(B_{j}-B_{U, j}\right)^{2}}{B_{U, j-1} B_{j}^{2}}}>1$. Since $G\left(\omega^{*}\right)=\exp (2 \gamma C)$ in the case with $K$ trading sessions, $G\left(\omega^{*}\right) * \prod_{j=K+1}^{j=L} \frac{1+\frac{c_{j}\left(B_{j}-B_{i, j}\right)^{2}}{B_{i, j-1} B_{j}^{2}}}{1+\frac{c_{j}\left(B_{j}-B_{U, j}\right)^{2}}{B_{U, j-1} B_{j}^{2}}}>\exp (2 \gamma C)$. It is obvious that the equilibrium fraction of informed investors in the case with additional trading sessions is higher than $\omega^{*}$.

When $C<C_{3}$, we can get the opposite conclusion following the similar logic.

Step 2: we study effects on additional trading opportunities on asset pricing. (a)The expected asset price is $\bar{D}-\frac{\bar{X}}{B_{j}}$. Since $B_{j}=h+\omega s+\frac{\omega^{2} s^{2}}{\gamma^{2}}+\sum_{k=1}^{j} c_{k}$, thus $B_{j}$ is an increasing function of $\omega$ and then we can conclude that expected asset price is also an increasing function of $\omega$.

(b) The market response to public information is $\frac{c_{k}}{B_{j}}$ which is a decreasing function of $\omega$.

(c) The price change volatility is

$$
\begin{gathered}
\operatorname{Var}\left(P_{j+1}-P_{j}\right)=\frac{c_{j+1}^{2}}{B_{j+1}^{2}} \operatorname{Var}\left(s_{c, j+1}-P_{j}\right) \\
=\frac{c_{j+1}^{2}}{B_{j+1}^{2}}\left[\frac{1}{c_{j+1}}+\operatorname{Var}\left(D-P_{j}\right)\right]=\frac{1}{B_{j}}-\frac{1}{B_{j+1}} \\
+\frac{c_{j+1}^{2}}{B_{j}^{2} B_{j+1}^{2}}\left(\omega s+\frac{\gamma^{2}}{q}\right) .
\end{gathered}
$$

The derivative of $\operatorname{Var}\left(P_{j+1}-P_{j}\right)$ with $\omega$ is:

$$
\begin{gathered}
-\frac{c_{j+1}}{B_{j}^{2} B_{j+1}}\left(s+2 \frac{\omega s^{2}}{\gamma^{2}}\right)-\frac{c_{j+1}}{B_{j} B_{j+1}^{2}}\left(s+2 \frac{\omega s^{2}}{\gamma^{2}}\right)+\frac{c_{j+1}^{2} s}{B_{j}^{2} B_{j+1}^{2}} \\
-\frac{2 c_{j+1}^{2}}{B_{j}^{3} B_{j+1}^{2}}\left(\omega s+\frac{\gamma^{2}}{q}\right)\left(s+2 \frac{\omega s^{2}}{\gamma^{2}}\right)-\frac{2 c_{j+1}^{2}}{B_{j}^{2} B_{j+1}^{3}}\left(\omega s+\frac{\gamma^{2}}{q}\right)\left(s+2 \frac{\omega s^{2}}{\gamma^{2}}\right) .
\end{gathered}
$$


since

$$
-\frac{c_{j+1} s}{B_{j}^{2} B_{j+1}}-\frac{c_{j+1} s}{B_{j} B_{j+1}^{2}}+\frac{c_{j+1}^{2} s}{B_{j}^{2} B_{j+1}^{2}}<0
$$

So we can conclude that first derivative of $\operatorname{Var}\left(P_{j+1}-P_{j}\right)$ with $\omega$ is negative and thus the price change volatility is a decreasing function of $\omega$.

Therefore, we can get the results in the proposition. 